\title{
Structural insights into the cross-neutralization of SARS- CoV and SARS-CoV-2 by the human monoclonal antibody
} 47D11

\author{
Juliette Fedry ${ }^{1 \dagger}$, Daniel L. Hurdiss ${ }^{1,2+}$, Chunyan Wang ${ }^{2 \dagger}$, Wentao Li $^{2 \dagger}$, Gonzalo Obal ${ }^{3}$, Ieva Drulyte ${ }^{4}$, Wenjuan \\ Du $^{2}$, Stuart C. Howes ${ }^{1}$, Frank J.M. van Kuppeveld ${ }^{2}$, Friedrich Förster ${ }^{*}$ Berend-Jan Bosch $^{{ }^{*}}$ \\ ${ }^{1}$ Cryo-Electron Microscopy, Bijvoet Center for Biomolecular Research, Department of Chemistry, Faculty of Science, Utrecht University, Padualaan 8, 3584 CH Utrecht, The \\ Netherlands. ${ }^{2}$ Virology Section, Infectious Diseases and Immunology Division, Department of Biomolecular Health Sciences, Faculty of Veterinary Medicine, Utrecht \\ University, 3584CL Utrecht, The Netherlands. ${ }^{3}$ Crystal and Structural Chemistry, Bijvoet Center for Biomolecular Research, Department of Chemistry, Faculty of Science, \\ Utrecht University, Padualaan 8, 3584 CH Utrecht, The Netherlands. "Materials and Structural Analysis, Thermo Fisher Scientific, Eindhoven, 5651 GG, The Netherlands. \\ †Contributed equally to this work.
}

*Corresponding author. Email: f.g.forster@uu.nl (F. F) and b.j.,bosch@uu.nl (B-J. B.)

The emergence of SARS-CoV-2 antibody escape-mutations highlights the urgent clinical need for broadly neutralizing therapeutics. We previously identified a potent human monoclonal antibody, 47D11, capable of cross-neutralizing SARS-CoV-2 and SARS-CoV, and protecting against the associated respiratory disease in an animal model. Here, we report cryo-EM structures of trimeric SARS-CoV and SARS-CoV-2 spike ectodomains in complex with the 47D11 Fab. 47D11 binds specifically to the closed conformation of the receptor-binding domain, distal to the ACE2 binding site. The CDRL3 stabilizes the N343 glycan in an upright conformation, exposing a conserved and mutationally constrained hydrophobic pocket, into which the CDRH3 loop inserts two aromatic residues. 47D11 stabilizes a partially open conformation of the SARSCoV-2 spike, suggesting that it could be used effectively in combination with other antibodies that target the exposed receptor-binding motif. Altogether, these results reveal a cross-protective epitope on the SARS-CoV-2 spike and provide a structural roadmap for the development of 47D11 as a prophylactic or post-exposure therapy for COVID-19.

\section{Introduction}

The severe acute respiratory syndrome coronavirus 2 (SARSCoV-2) emerged from a zoonotic event in China, late 2019 (1). As of February 4th, 2021, the resulting coronavirus induced disease 19 (COVID-19) pandemic has been responsible for over 100 million infections and over two million deaths (https://covid19.who.int/). SARS-CoV-2 and SARS-CoV, another highly lethal respiratory pathogen which emerged in 2002/2003 (2), belong to the Sarbecovirus subgenus (genus Betacoronavirus, family Coronaviridae) (3). There is an urgent clinical need for potent antiviral therapies to halt the spread of SARS-CoV-2 and to pre-empt future outbreaks caused by SARS-like viruses. Antibodies are a promising class of drugs for combatting infectious diseases and have shown therapeutic efficacy for a number of viruses $(4,5)$, including in the treatment of SARS and COVID-19 $(6,7)$. Such antibodies function by targeting vulnerable sites on viral surface proteins.

The coronavirus trimeric spike (S) glycoprotein, located on the viral envelope, is the key mediator of viral entry into host cells. The spike protein is made of two subunits: S1 is involved in receptor binding and $\mathrm{S} 2$ in membrane fusion. The
S1 subunit itself is further subdivided into an N-terminal domain (NTD, or S1A) and a receptor binding domain (RBD, or S1B) $(8,9)$. The spike proteins of SARS-CoV-2 (SARS2-S; 1273 residues, strain Wuhan-Hu-1) and SARS-CoV (SARS-S, 1255 residues, strain Urbani) exhibit $77.5 \%$ identity in their amino acid sequence and are structurally conserved (10-13). The spike trimer exists in equilibrium between a closed conformation, where all three RBDs lie flat in a "down" conformation, and a partially open conformation, where on RBD adopts an "up" conformation and is exposed for receptor engagement (10-13). Both viruses use the human angiotensin converting enzyme 2 (ACE2) protein as a host receptor, with binding mediated through interactions with the receptorbinding motif (RBM) located on the RBD, and the N-terminal helix of ACE (14). The spike-mediated fusion of viral and cellular membranes is tightly regulated and triggered by a cascade of preceding events. The first step involves the attachment of SARS-CoV-2 to the target cell surface via the interaction between spike and ACE2 $(14,15)$. In the second step, the spike protein needs to be primed for membrane fusion by host proteases (e.g., cellular transmembrane serine protease 2) which cleave the spike at multiple sites (16), 
enabling shedding of S1. Finally, the free S2 catalyzes the fusion of the viral and the host membranes $(17,18)$, causing the release of the viral genome into the host cell cytoplasm.

The S glycoprotein is the primary target for neutralizing antibodies, making it the main target for vaccine development (19). Indeed, a number of SARS-CoV-2 neutralizing antibodies have now been described (20-34). The most commonly identified antibodies neutralize coronaviruses by binding to the RBM in S1, blocking receptor interactions and/or promoting a premature S1 shedding and conformational change of spike to the post-fusion state. However, a number of recently identified SARS-CoV-2 variants (B.1.1.7 (35), B.1.351 (36), B.1.1.28.1 (P.1) (37), B.1.1.28.2 (P.2) (38) (39)) harbor mutations in the RBM (K417N/T, E484K and N501Y), which could facilitate viral escape from monoclonal antibodies binding to this region (40-42), as well as some polyclonal sera dominated by this class of antibodies (43). Fewer antibodies have been reported to bind epitopes that are distal to the ACE2 binding site. Such antibodies target the RBD-core $(28,44-47)$, or the NTD (48).

Cross-neutralizing antibodies are highly valuable in the development of antiviral therapeutics as they confer a broader protection and mitigate the risk of immune escape. However, conserved SARS-CoV and SARS-CoV-2 cross-protective epitopes appear to be rarely targeted by neutralizing antibodies $(44,45,47,49,50)$ and only a handful of crossneutralizing antibodies have been structurally characterized (44-47). Combined structural and functional studies are thus required to delineate epitopes eliciting cross-neutralizing antibodies and guide vaccine and antiviral development applicable to a wide range of future SARS-CoV-2 variants in the treatment of COVID-19 (51).

We recently reported the potent human monoclonal antibody, 47D11, capable of cross-neutralizing SARS-CoV and SARS-CoV-2 at 1.3 and $3.8 \mathrm{nM}$, respectively, without competing with ACE2 binding (52). Subsequent pre-clinical studies revealed 47D11 prophylactic potential to prevent SARS-CoV-2 induced pneumonia in a hamster model (53). Here we employed structural and functional studies to decipher the molecular basis for 47D11-mediated cross-neutralization.

\section{Results and Discussion \\ 47D11 specifically recognizes the down conformation of the receptor binding domain}

To understand how 47D11 binds to the SARS-CoV and SARSCoV-2 spike proteins, we used cryo-electron microscopy (cryo-EM) single particle analysis to determine structures of prefusion stabilized ectodomain trimers in complex with the 47D11 Fab fragment. The resulting cryo-EM maps have global resolutions of $3.8 \AA$ and $4.0 \AA$ resolution for SARS-S and SARS2-S, respectively (Supplementary Figure1A-F). For previously reported apo $\mathrm{S}$ trimers, both the open and closed conformation are observed, with the latter being predominant (56\% for SARS-S (11) and 67\% for SARS2-S (12)). Upon incubation with 47D11, only the closed conformation of the SARS-CoV spike was observed, with stochiometric binding of 47 D11 to each RBD (Figure 1A). Interestingly, for SARS-CoV2 , only the partially open conformation of spike was observed, with one Fab bound to each of the two RBDs in down conformation, and the remaining RBD in up conformation unoccupied and, in principle, accessible to ACE2 binding (Figure 1B). The sub-stochiometric binding observed for SARS2-S may partially explain our previous observations that 47D11 binds to the SARS-S with higher affinity than SARS2-S (equilibrium dissociation constant $\left[\mathrm{K}_{\mathrm{D}}\right]$ of $0.745 \mathrm{nM}$ and $10.8 \mathrm{nM}$, respectively) (52).

To understand why 47D11 favors different spike conformations for SARS-CoV and SARS-CoV-2, we first superposed the Fab-bound structures on their apo counterparts. Compared to the apo partially open SARS2-S structure, the RBDs are less compact when 47D11 is bound (Figure 2A). The apo down conformation of the RBD would preclude binding of 47D11 to the adjacent RBD through steric hindrance. To accommodate the bound Fab on the latter, the first RBD shifts outwards by $\sim 7 \AA$ (Figure 2B). Unlike Mabs S309 and H014 $(44,47)$, two other RBD-core targeting cross-neutralizing antibodies, there was no indication from our cryo-EM data that $47 D 11$ can bind to the up conformation of the SARS2-S RBD. In line with this observation, superimposition of the closed and open SARS2-S RBDs revealed that 47D11 would clash with the adjacent N-terminal domain (NTD) and the N331 glycan in the latter conformation (Figure 2C).

Similar to SARS2-S, the RBDs of the 47D11 bound SARS-S are also less compact than the reported apo fully closed structure (Figure 2D). In contrast to SARS2-S, there is a potential stabilizing salt bridge between SARS-S D463, located on the receptor binding ridge, and R18 on the 47D11 light chain (Figure $2 \mathrm{E}$ ). Indeed, this ridge exhibits the most prominent structural differences between SARS2-S and SARS-S (14). This epitope distal loop, located within the ACE2-binding region, contains an essential disulfide bridge in both viruses, but is more compact in SARS-S. To test whether the epitope distal ridge impacts binding of 47D11 to the SARS-S and SARS2-S, we swapped loop residues 470-490 (SARS2-S numbering) and produced chimeric ectodomains. We also introduced a D463A mutation in SARS-S to disrupt the observed salt bridge (Figure 2E). In support of our hypothesis, the SARS2S containing the SARS-S loop, exhibited increased binding to 47D11, whereas the SARS-S D463A mutant displayed decreased binding to 47D11 and loss of ACE2 binding (Figure S4A-B), consistent with previous reports (54). However, we did not observe an equivalent loss of binding for the chimeric SARS-S, suggesting that other differences in protein sequence or quaternary structure may be involved (Figure 2F). Taken 
together, our data show that 47D11 binding to the RBD has differing outcomes for SARS-S and SARS2-S, trapping them in the fully closed and the partially open conformation, respectively (Figure S2).

These results rationalize our previous observation that the 47D11-bound SARS2-S can still bind soluble ACE2 in a cell staining assay (52), given that it has one open RBD accessible to the receptor. It is unclear, however, how the 47D11-bound SARS-S, stabilized with the 3 RBDs in the down conformation, can also bind ACE2 (42). The 47D11-bound RBDs may be able to adopt a semi-open conformation, too transient to be visualized by cryo-EM, which could accommodate both 47D11 and ACE2 binding (55). Alternatively, it is possible that 47D11 binding results in destabilization of the spike trimer leading to the separation of the protomers and exposure of the ACE2 binding site, as reported for CR3022 (56). Similarly to S309 (35), the absence of competition between 47D11 and ACE2 complicates the determination of the exact neutralization mechanism. First, as viral membrane fusion is a tightly controlled process, it is possible that the perturbation of the spike conformational flexibility induced by 47D11 binding, hinders the correct and timely S1 shedding and subsequent conformational changes required for fusion. It is also possible that IgG specific bivalent mechanisms like spike cross-linking, steric hindrance or virus aggregation are involved. Ultimately, further studies are required to fully decipher the neutralization mechanisms of 47D11.

\section{D11 targets a conserved hydrophobic pocket in the $\boldsymbol{R B D}$}

The 47D11 epitope is distinct from the ACE2 binding site (Figure $3 \mathrm{~A}$ ), rationalizing its ability to cross-neutralize SARS-CoV and SARS-CoV-2 independently of receptor-binding inhibition (52). The protein/glycan epitope is located on the core domain of the SARS-S and SARS2-S RBD. As expected, the mode of binding is highly similar for SARS-S and SARS2-S (Figure S3A-C), with the aligned 47D11:RBD complexes deviating by an RMSD value of $1.4 \AA$ per $201 \mathrm{C} \alpha$ atoms.

The paratope is composed of CDRL3 and CDRH3 loops, which form a primarily hydrophobic interaction burying an RBD surface area of $\sim 830 \AA^{2}$ and $\sim 800 \AA^{2}$ for SARS-S and SARS2-S, respectively. The side chain of 47D11 CDRL3 tryptophan W94 stacks against the N330/N343 (SARS/SARS2) glycan tree, contributing to its stabilization in an upright conformation (Figure 3B). The structure revealed a hydrophobic pocket into which the CDRH3 loop projects, allowing Fab residues W102 and F103 to interact with RBD core residues F338, F342, Y365, V367, L368, F374 and W436 (F325, F329, Y352, V354, L355, F361 and W423 in SARS-S) - Figure $3 \mathrm{~B}$ and S3B. Interestingly, this pocket is shielded by the N343 glycan in previously reported apo SARS2-S structures (Figure $3 \mathrm{C}-\mathrm{D})(12,13)$.
In order to accommodate the CDRH3 loop residues, the helix encompassing residues $365-370$ is displaced outwards by $2 \AA$, creating $55 \AA^{3}$ of solvent accessible volume, which is not present in the apo RBD (Figure 3C-D and Figure S3E-F). Of note, the region directly below this hydrophobic pocket was recently shown to bind to linoleic acid, which stabilizes the closed conformation of spike by spanning two adjacent RBDs (57). In the 47D11-bound RBD, the position of the helix encompassing residues $365-370$ would preclude binding of linoleic acid (Figure S3E). Consistent with this arrangement, no density corresponding to linoleic acid could be detected in any of our reconstructions.

To verify the 47D11 epitope, we introduced single alanine mutations into full-length SARS2-S and expressed these at the surface of HEK 293T cells. In addition, we generated a spike mutant with the naturally occurring V367F minority variant (58). Total cellular expression of mutants was comparable to wildtype spike protein as demonstrated by an antibody targeting the C-terminal appended Flag-tag on the spike proteins (Figure S4C). Binding of 47D11 to cell surface expressed wildtype and mutant spike proteins was assessed by flow cytometry. As controls, we used the soluble Fc-tagged ACE2, as well as the RBD core-targeting mAb CR3022 (28) and the mAb 49F1, which binds $\mathrm{S} 1$ outside the RBD (52). Similar binding levels of the $49 \mathrm{~F} 1$ antibody in wild type and mutant spike proteins confirmed the correct cell surface localization of the mutants (Figure $3 \mathrm{H}$ ). Mutations of V367 to a phenylalanine or an alanine had only a minor effect on 47D11 antibody binding (Figure 3E), consistent with data showing that this polymorphism had no effect on neutralization of SARS2-S pseudotyped virus (Figure 3I). Collectively, these data indicate that 47D11 would be effective against this SARS-CoV-2 variant. In contrast, all other amino acid substitutions in the hydrophobic core not only reduced 47D11 binding (Figure 3E), but also prevented binding of ACE2 and of the core targeting antibody CR3022, despite being distal to their respective interaction sites on the RBD (Figure 3F-G and Figure S5A-B). These results suggest that these mutations have an effect on the tertiary structure of the whole RBD including the distal ACE2 binding ridge.

In line with this explanation, a recent study reported deep mutational scanning of SARS2-S RBD residues, revealing how mutation of each of the RBD residues affects expression of folded protein and its affinity for ACE2 (59). When the mean mutation effect on expression was mapped on the 47D11 bound RBD, we observed that the hydrophobic pocket, targeted by 47D11, is highly mutationally constrained (Figure $3 \mathrm{~J})$. Altogether, the mutational space in the 47D11 epitope region appears to be strongly limited by a concomitant loss of ACE2 binding, possibly lowering the risk of immune escape.

The 47D11 epitope matches a region of the RBD earlier described as relatively "immune silent" (46). It is distinct 
from other reported RBD-core targeting antibodies/nanobodies, such as CR3022, H014 and VHH-72 (Figure S5A) (28, 47, $60)$. Another SARS-CoV and SARS-CoV-2 cross-neutralizing antibody identified from memory B cells of a SARS-CoV patient, S309, targets a similar region to 47D11, but here the orientation of the N343 glycan prohibits access to the hydrophobic pocket, similarly to apo structures (Figure $3 \mathrm{~K}$ and S5A) (44). The quaternary epitopes of the SARS-CoV-2 neutralizing antibodies C144 (61) and S2M11 (62), isolated from COVID-19 recovering patients, also include the conserved hydrophobic pocket targeted by 47D11 (Figure S5B). However, the C144 and S2M11 epitopes extend to the RBM of the adjacent RBD, which is not conserved between SARS-CoV and SARS-CoV-2. Our data show that the 47D11 epitope, being restricted to a single RBD core, accounts for its cross-neutralization ability, while C144 and S2M11 fail to neutralize SARS$\mathrm{CoV}$.

\section{D11 neutralizes emerging $S A R S$-CoV-2 variants}

Recently emerged SARS-CoV-2 variants carry RBD mutations, which localize to the ACE2 binding motif, namely K417N, E484K and N501Y (Figure 4A). While these mutations are distal to the 47D11 binding site, our data reveals crosstalk between the RBM and the core region targeted by 47D11, as mutations in the 47D11 epitope resulted in loss of ACE2 binding (Figure 3F-G). Reciprocally, we analyzed the effect of emerging mutations in the RBM on 47D11's neutralization ability by introducing the K417N, E484K or N501Y mutation into SARS2-S pseudotyped VSV. Our data show that 47D11 neutralization efficiency is not affected by these single mutations in the RBM (Figure 4B), making 47D11 a promising therapeutic candidate in the fight against the new, fast spreading SARS-CoV-2 variants.

\section{$47 D 11$ displays broader reactivity among at-risk bat coronaviruses}

In order to assess whether 47D11 has broad reactivity, we analyzed 47D11 binding to the recombinantly expressed RBDs of 3 SARS-like bat betacoronaviruses: the sarbecoviruses WIV16 and HKU3-3, and the more distant nobecovirus HKU9-3 (Figure 5A). Comparative sequence analysis revealed that the 47D11 epitope is highly conserved across circulating SARS-like sarbecoviruses (Figure 5B and S6). This is in contrast to the ACE2 binding region, which exhibits the greatest sequence variability. The results demonstrated that 47D11 binds to the WIV16 RBD with similar affinity to SARS-S and SARS2-S (Figure 5C) and neutralizes WIV16-S pseudotyped VSV with an IC50 value of $0.165 \mu \mathrm{g} / \mathrm{ml}$ (Figure 5D). In contrast, 47D11 does not bind the RBDs of HKU3-3 and HKU9-3 (Figure 5C). HKU9-3 has the most distantly related RBD sequence to SARS-CoV-2 and the N343 glycosylation site, as well as the hydrophobic residues of the 47D11 epitope, are not conserved, explaining lack of antibody binding (Figure 5E). In both WIV16 and HKU3-3 the 47D11 epitope is conserved but HKU3-3 displays 4 amino acid variations introducing charges in close proximity to 47D11: L335R, 339GE340 to DK and N360D, which could preclude 47D11 binding. Of note, unlike WIV16, neither HKU3-3 nor HKU9-3 is able to bind human ACE2 (63-65). Sarbecoviruses (which include SARS-CoV, SARS-CoV-2, numerous bat and a few pangolin viruses) are considered to be a high-risk group for potential emergence (63). Both sarbecoviruses that cause human disease, SARSCoV and SARS-CoV-2, use the human ACE2 for cell entry and hence it is thought to be a trait for particular importance in the emergence pathway of sarbecoviruses (63). Our results provide a proof of principle that 47D11 could contribute to treatments for future outbreaks caused by ACE2-dependent SARS-like viruses.

In summary, our structural and functional studies demonstrate that 47D11 achieves cross-neutralization of the sarbecoviruses SARS-CoV-2 and SARS-CoV, by targeting a glycan shielded, conserved pocket on the spike RBD. This cryptic site of vulnerability offers an attractive target for the design of cross protective vaccines and targeted therapeutics. Genetic diversity of SARS-CoV-2 has recently increased and the genetic/antigenic variation will rise further in time, as observed for the endemic human coronavirus HCoV-229E, which exhibits cumulative sequence variation in the RBD loops engaging its cellular receptor (66). The conserved nature of the glyco-epitope, evolutionary constrained by limited mutational space, may confer the 47D11 antibody sustainable applicability in neutralizing a wide range of future-emerging virus variants. Antibody combinations targeting non-overlapping epitopes are currently of high interest as they may act synergistically permitting a lower dosage and an increased barrier to immune escape (62). In this respect, and unlike C144 (61) and S2M11 (62), which lock the SARS2-S in its closed conformation, our structural data shows that 47D11 stabilizes the partially open conformation of the SARS2-S. This may render the spike more susceptible to other monoclonal antibodies which target epitopes only exposed in the RBD up conformation - like H014, CR3022 or antibodies targeting the ACE2 binding ridge, thus making 47D11 a prime candidate for combination treatment.

Altogether our results delineate a conserved vulnerability site on the SARS-CoV-2 spike and provide a fundamental insight to support the rational development of antibody-based interventions in the treatment of COVID-19.

\section{Methods \\ Expression and purification of coronavirus spike pro- teins}

To express the prefusion spike ectodomain, gene encoding residues 1-1200 of SARS2 S (GenBank: QHD43416.1) with 
proline substitutions at residues 986 and 987, a "AAARS" substitution at the furin cleavage site (residues 682-685) and residues 1-1160 of SARS S (GenBank: AAP13567.1) with proline substitutions at residues 956 and 957, a C-terminal T4 fibritin trimerization motif, a StrepTag was synthesized and cloned into the mammalian expression vector pCAGGS. Similarly, pCAGGS expression vectors encoding $\mathrm{S} 1$ or its subdomain $\mathrm{S1}_{\mathrm{B}}$ of SARS (S1, residues 1-676; $\mathrm{S1}_{\mathrm{B}}$, residues, 325-533), and SARS2 (S1, residues 1-682; $\mathrm{S1}_{\mathrm{B}}$, residues 333-527) C-terminally tagged with Fc domain of human or mouse IgG or Strep-tag were generated as described before (52). Recombinant proteins and antibody 47D11 were expressed transiently in FreeStyle $^{\mathrm{TM}}$ 293-F Cells (Thermo Fisher Scientific) and affinity purified from the culture supernatant by protein-A sepharose beads (GE Healthcare) or streptactin beads (IBA) purification. Purity and integrity of all purified recombinant proteins was checked by coomassie stained SDS-PAGE.

\section{ELISA analysis of antibody binding to CoV spike anti- gens}

ELISA was performed as described previously (52). Briefly, NUNC Maxisorp plates (Thermo Scientific) coated with equimolar antigen amounts were blocked with $3 \%$ bovine serum albumin (Bio-Connect) in PBS containing 0.1\% Tween20 at RT for 2 hours. Fourfold serial dilutions of mAbs starting at $10 \mu \mathrm{g} / \mathrm{ml}$ (diluted in blocking buffer) were added and plates were incubated for 1 hour at RT. Plates were washed three times and incubated with horseradish peroxidase (HRP)-conjugated goat anti-human secondary antibody (ITK Southern Biotech) diluted 1:2000 in blocking buffer for 1 hour at RT. An HRP-conjugated anti-StrepMAb (IBA) antibody was used to corroborate equimolar coating of the Strep-tagged spike antigens. HRP activity was measured at 450 nanometer using tetramethylbenzidine substrate (BioFX) using an ELISA plate reader (EL-808, Biotek). Half-maximum effective concentration $\left(\mathrm{EC}_{50}\right)$ binding values were calculated by nonlinear regression analysis on the binding curves using GraphPad Prism (version 8).

\section{Pseudotyped virus neutralization assay}

Neutralization with SARS2-S (GenBank: HD43416.1) and WIV16-S (GenBank: ALK02457.1) VSV pseudotyped viruses was performed as described previously (52). HEK-293T cells were transfected with pCAGGS expression vectors encoding SARS2-S carrying an 18-a.a. or WIV16-S carrying a 19-a.a. cytoplasmic tail truncation, respectively. One day post transfection, cells were infected with the VSV-G pseudotyped VSV $\triangle \mathrm{G}$ expressing the firefly (Photinus pyralis) luciferase. Twentyfour hours later, cell supernatants containing SARS2-S or WIV16-S pseudotyped VSV particles were harvested and titrated on African green monkey kidney VeroE6 (ATCC\#CRL1586) cells. In the virus neutralization assay, mAbs were threefold serially diluted and mixed with an equal volume of pseudotyped VSV particles and incubated for 1 hour at room temperature (RT). The virus/antibody mix was subsequently added to confluent VeroE6 monolayers in 96-well plate, and incubated at $37^{\circ} \mathrm{C}$. After 24 hours, cells were washed and lysis buffer (Promega) was added. Luciferase activity was measured on a Berthold Centro LB 960 plate luminometer using D-luciferin as a substrate (Promega). The percentage of infectivity was calculated as ratio of luciferase readout in the presence of mAbs normalized to luciferase readout in the absence of $\mathrm{mAb}$. The half maximal inhibitory concentration $\left(\mathrm{IC}_{50}\right)$ was determined using 4-parameter logistic regression (GraphPad Prism version 8).

\section{Flow cytometry-based antibody binding assay}

Antibody binding to full length SARS2-S epitope mutants on the cell surface was measured by flow cytometry. HEK-293T cells were seeded at a density of $2.5 \times 10^{5}$ cells per ml in a T25 flask. After reaching $80 \%$ confluency, cells were transfected with an expression plasmid encoding full length SARS2-S mutants with C-terminal Flag tag - using Lipofectamine 2000 (Invitrogen). 24 hours post transfection, cells were dissociated by cell dissociation solution (Sigma-aldrich, Merck KGaA; cat. no. C5914). To detect total spike expression, cells were permeabilized by $0.2 \%$ saponin and subjected to antiFlag tag antibody staining. For cell surface antibody binding measurement, intact (non-permeabilized) cells were incubated with $20 \mu \mathrm{g} / \mathrm{ml}$ of 47D11, ACE2-Fc, CR3022 (target SARS2 RBD core), 49F1 (target SARS2-S1 outside RBD) and anti-Flag (Sigma, F1804) for 1h on ice, followed by incubation with 1:200 diluted Alexa Fluor 488 conjugated goat anti-human IgG antibodies (Invitrogen, Thermo Fisher Scientific, \# A-11013) or goat anti-mouse IgG antibodies (Invitrogen, Thermo Fisher Scientific, \# A28175) for $45 \mathrm{~min}$ at room temperature. Cells were subjected to flow cytometric analysis with a CytoFLEX Flow Cytometer (Beckman Coulter). The results were analyzed with FlowJo (version 10). FSC/SSC gates were used to select mononuclear cells. Control antibody staining was used to define positive/negative cell populations.

\section{Preparation of Fab-47D11 from IgG}

47D11 Fab was digested from IgG with papain using a Pierce Fab Preparation Kit (Thermo Fisher Scientific), following the manufacturer's standard protocol.

\section{Cryo-EM sample preparation and data collection}

$3 \mu \mathrm{L}$ of SARS2-S or SARS-S at $1.6 \mathrm{mg} / \mathrm{mL}$ was mixed with 0.85 $\mu \mathrm{L}$ of $\mathrm{Fab} 47 \mathrm{D} 11$ at $4 \mathrm{mg} / \mathrm{mL}$ and incubated for $50 \mathrm{~s}$ at RT. The sample was applied onto a freshly glow discharged R1.2/1.3 Quantifoil grid in a Vitrobot Mark IV (Thermo Fisher Scientific) chamber pre-equilibrated at $4^{\circ} \mathrm{C}$ and $100 \%$ 
humidity. The grid was immediately blotted at force 0 for $5 \mathrm{~s}$ and plunged into liquid ethane. Data was acquired on a 200 kV Talos Arctica (Thermo Fisher Scientific) equipped with a Gatan K2 Summit direct detector and Gatan Quantum energy filter operated in zero-loss mode with a $20 \mathrm{eV}$ slit width. To account for the preferred orientation exhibited by the spike ectodomains, automated data collection at tilts $0^{\circ}, 20^{\circ}$, and $30^{\circ}$ was carried out using EPU 2 software (Thermo Fisher Scientific), and data at tilt $40^{\circ}$ using SerialEM (67). A nominal magnification of 130,000x, corresponding to an effective pixel size of $1.08 \AA$, was used. Movies were acquired in counting mode with a total dose of $40 \mathrm{e} / \AA^{2}$ distributed over 50 frames. 4,231 movies were acquired for SARS2 and 3,247 movies for SARS-S, with defocus ranging between $0.5 \mu \mathrm{m}$ and $3 \mu \mathrm{m}$.

\section{Cryo-EM data processing}

Single-particle analysis was performed in Relion version 3.1. (68). The data was processed in four separate batches, corresponding to the stage tilt angle used for the acquisition. Drift and gain correction were performed with MotionCor2 (69), CTF parameters were estimated using CTFFind4 (70) and particles were picked using the Laplacian picker in Relion (68). One round of 2D classification was performed on each batch of data and particles belonging to well defined classes were retained. Subsequently, 3D classification was performed, using a $50 \AA \AA$ low-pass filtered partially open conformation as an initial model [EMD-21457, (13)], without imposing symmetry. All particles belonging to Fab bound class were then selected for 3D auto-refinement. Before merging the different batches, iterative rounds of per particle CTF refinement, 3D auto-refinement and post-processing were used to account for the stage tilt used during data collection. The refined particle star files from each batch were then combined and subjected to a final round of 3D auto refinement, per particle defocus estimation, 3D auto-refinement and post processing, both with and without imposed C3 symmetry. Overviews of the single-particle image processing pipelines are shown in supplementary figures 7 and 8 .

\section{Model building and refinement}

UCSF Chimera (version 1.12.0) and Coot (version, 1.0.) were used for model building and analysis $(71,72)$. The SARS2-S model, in the partially open conformation (one RBD up, pdb 6VYB) (13), was used for the spike and fitted into our density using the UCSF Chimera 'Fit in map' tool (71). For SARS a closed protomer of the pdb $6 \mathrm{NB} 6$ was used as starting model (73). To build a model for the Fab the sequence of the variable regions of the $\mathrm{HC}$ and the $\mathrm{LC}$ were separately blasted against the $\mathrm{pdb}$. For the $\mathrm{HC}$ variable region, the corresponding region of the pdb 6IEB (human monoclonal antibody R15 against RVFV Gn) was used (74). The LC variable region was modelled using the pdb 6FG1 as template (Fab Natalizumab) (75).
For both chains, the query sequence of 47D11 was aligned to the template sequence. Sequence identity was particularly high ( $87 \%$ and $97 \%$ for the $\mathrm{HC}$ and LC, respectively). Phenix sculptor was used to create an initial model for the Fab chains (76), removing the non-aligning regions (notably the CDRH3). This model was fitted into our density and the missing regions were built manually in the density map using Coot (72). Models were refined against the respective EM density maps using Phenix Real Space Refinement and Isolde (77, 78), and validated with MolProbity (79) and Privateer (glycans) $(80,81)$.

\section{Analysis and visualization}

PDBePISA was used to identify spike residues interacting with 47D11 (82). Surface coloring of the SARS-CoV-2 RBD using the Kyte-Doolittle hydrophobicity scale was performed in UCSF chimera (71). Volume measurements were performed using CASTp 3.0, using a probe radius of $1.2 \AA$ (83). In order to color the 47D11 bound RBD surface according to each residues mean mutational effect on expression, the pdb file was populated with the mean mutation effect on expression values described by Starr et al. (59). The UCSF Chimera 'MatchMaker' tool was used to obtain RMSD values, using default settings. Figures were generated using UCSF Chimera (71) and UCSF ChimeraX (84).

\section{REFERENCES AND NOTES}

1. P. Zhou, X.-L. Yang, X.-G. Wang, B. Hu, L. Zhang, W. Zhang, H.-R. Si, Y. Zhu, B. Li, C.L. Huang, H.-D. Chen, J. Chen, Y. Luo, H. Guo, R.-D. Jiang, M.-Q. Liu, Y. Chen, X.-R. Shen, X. Wang, X.-S. Zheng, K. Zhao, Q.-J. Chen, F. Deng, L.-L. Liu, B. Yan, F.-X. Zhan, Y.-Y. Wang, G.-F. Xiao, Z.-L. Shi, A pneumonia outbreak associated with a new coronavirus of probable bat origin. Nature 579, 270-273 (2020). doi:10.1038/s41586-020-2012-7 Medline

2. T. G. Ksiazek, D. Erdman, C. S. Goldsmith, S. R. Zaki, T. Peret, S. Emery, S. Tong, C. Urbani, J. A. Comer, W. Lim, P. E. Rollin, S. F. Dowell, A.-E. Ling, C. D. Humphrey, W.-J. Shieh, J. Guarner, C. D. Paddock, P. Rota, B. Fields, J. DeRisi, J.-Y. Yang, N. Cox, J. M. Hughes, J. W. LeDuc, W. J. Bellini, L. J. Anderson; SARS Working Group, A novel coronavirus associated with severe acute respiratory syndrome. N. Engl. J. Med. 348, 1953-1966 (2003). doi:10.1056/NEJMoa030781 Medline

3. Coronaviridae Study Group of the International Committee on Taxonomy of Viruses, The species Severe acute respiratory syndrome-related coronavirus: classifying 2019-nCoV and naming it SARS-CoV-2. Nat. Microbiol. 5, 536-544 (2020).

4. P. Prabakaran, Z. Zhu, X. Xiao, A. Biragyn, A. S. Dimitrov, C. C. Broder, D. S. Dimitrov, Potent human monoclonal antibodies against SARS CoV, Nipah and Hendra viruses. Expert Opin. Biol. Ther. 9, 355-368 (2009). doi:10.1517/14712590902763755 Medline

5. E. O. Saphire, S. L. Schendel, B. M. Gunn, J. C. Milligan, G. Alter, Antibody-mediated protection against Ebola virus. Nat. Immunol. 19, 1169-1178 (2018). doi:10.1038/s41590-018-0233-9 Medline

6. A. Casadevall, L. A. Pirofski, The convalescent sera option for containing COVID-19. J. Clin. Invest. 130, 1545-1548 (2020). doi:10.1172/JCl138003 Medline

7. A. C. Cunningham, H. P. Goh, D. Koh, Treatment of COVID-19: Old tricks for new challenges. Crit. Care 24, 91 (2020). doi:10.1186/s13054-020-2818-6 Medline

8. F. Li, Structure, Function, and Evolution of Coronavirus Spike Proteins. Annu. Rev. Virol. 3, 237-261 (2016). doi:10.1146/annurev-virology-110615-042301 Medline

9. B. J. Bosch, R. van der Zee, C. A. de Haan, P. J. Rottier, The coronavirus spike protein is a class I virus fusion protein: Structural and functional characterization of the fusion core complex. J. Virol. 77, 8801-8811 (2003). doi:10.1128/JVl.77.16.8801- 
8811.2003 Medline

10. M. Gui, W. Song, H. Zhou, J. Xu, S. Chen, Y. Xiang, X. Wang, Cryo-electron microscopy structures of the SARS-CoV spike glycoprotein reveal a prerequisite conformational state for receptor binding. Cell Res. 27, 119-129 (2017). doi:10.1038/cr.2016.152 Medline

11. Y. Yuan, D. Cao, Y. Zhang, J. Ma, J. Qi, Q. Wang, G. Lu, Y. Wu, J. Yan, Y. Shi, X. Zhang, G. F. Gao, Cryo-EM structures of MERS-CoV and SARS-CoV spike glycoproteins reveal the dynamic receptor binding domains. Nat. Commun. 8, 15092 (2017). doi:10.1038/ncomms15092 Medline

12. D. Wrapp, N. Wang, K. S. Corbett, J. A. Goldsmith, C.-L. Hsieh, O. Abiona, B. S. Graham, J. S. McLellan, Cryo-EM structure of the 2019-nCoV spike in the prefusion conformation. Science 367, 1260-1263 (2020). doi:10.1126/science.abb2507 Medline

13. A. C. Walls et al., Structure, Function, and Antigenicity of the SARS-CoV-2 Spike Glycoprotein. Cell 181, 281-292 e286 (2020).

14. J. Lan, J. Ge, J. Yu, S. Shan, H. Zhou, S. Fan, Q. Zhang, X. Shi, Q. Wang, L. Zhang, X. Wang, Structure of the SARS-CoV-2 spike receptor-binding domain bound to the ACE2 receptor. Nature 581, 215-220 (2020). doi:10.1038/s41586-020-2180-5 Medline

15. R. Yan, Y. Zhang, Y. Li, L. Xia, Y. Guo, Q. Zhou, Structural basis for the recognition of SARS-CoV-2 by full-length human ACE2. Science 367, 1444-1448 (2020). doi:10.1126/science.abb2762 Medline

16. M. Hoffmann et al., SARS-CoV-2 Cell Entry Depends on ACE2 and TMPRSS2 and Is Blocked by a Clinically Proven Protease Inhibitor. Cell 181, 271-280 e278 (2020).

17. A. C. Walls, M. A. Tortorici, J. Snijder, X. Xiong, B.-J. Bosch, F. A. Rey, D. Veesler, Tectonic conformational changes of a coronavirus spike glycoprotein promote membrane fusion. Proc. Natl. Acad. Sci. U.S.A. 114, 11157-11162 (2017). doi:10.1073/pnas.1708727114 Medline

18. Y. Cai, J. Zhang, T. Xiao, H. Peng, S. M. Sterling, R. M. Walsh Jr., S. Rawson, S. RitsVolloch, B. Chen, Distinct conformational states of SARS-CoV-2 spike protein. Science 369, 1586-1592 (2020). doi:10.1126/science.abd4251 Medline

19. D. van Riel, E. de Wit, Next-generation vaccine platforms for COVID-19. Nat. Mater. 19, 810-812 (2020). doi:10.1038/s41563-020-0746-0 Medline

20. J. Hansen, A. Baum, K. E. Pascal, V. Russo, S. Giordano, E. Wloga, B. O. Fulton, Y. Yan, K. Koon, K. Patel, K. M. Chung, A. Hermann, E. Ullman, J. Cruz, A. Rafique, T. Huang, J. Fairhurst, C. Libertiny, M. Malbec, W. Y. Lee, R. Welsh, G. Farr, S. Pennington, D. Deshpande, J. Cheng, A. Watty, P. Bouffard, R. Babb, N. Levenkova, C. Chen, B. Zhang, A. Romero Hernandez, K. Saotome, Y. Zhou, M. Franklin, S. Sivapalasingam, D. C. Lye, S. Weston, J. Logue, R. Haupt, M. Frieman, G. Chen, W. Olson, A. J. Murphy, N. Stahl, G. D. Yancopoulos, C. A. Kyratsous, Studies in humanized mice and convalescent humans yield a SARS-CoV-2 antibody cocktail. Science 369, 1010-1014 (2020). doi:10.1126/science.abd0827 Medline

21. P. J. M. Brouwer, T. G. Caniels, K. van der Straten, J. L. Snitselaar, Y. Aldon, S. Bangaru, J. L. Torres, N. M. A. Okba, M. Claireaux, G. Kerster, A. E. H. Bentlage, M. M. van Haaren, D. Guerra, J. A. Burger, E. E. Schermer, K. D. Verheul, N. van der Velde, A. van der Kooi, J. van Schooten, M. J. van Breemen, T. P. L. Bijl, K. Sliepen, A. Aartse, R. Derking, I. Bontjer, N. A. Kootstra, W. J. Wiersinga, G. Vidarsson, B. L. Haagmans, A. B. Ward, G. J. de Bree, R. W. Sanders, M. J. van Gils, Potent neutralizing antibodies from COVID-19 patients define multiple targets of vulnerability. Science 369, 643-650 (2020). doi:10.1126/science.abc5902 Medline

22. R. Shi, C. Shan, X. Duan, Z. Chen, P. Liu, J. Song, T. Song, X. Bi, C. Han, L. Wu, G. Gao, X. Hu, Y. Zhang, Z. Tong, W. Huang, W. J. Liu, G. Wu, B. Zhang, L. Wang, J. Qi, H. Feng, F.-S. Wang, Q. Wang, G. F. Gao, Z. Yuan, J. Yan, A human neutralizing antibody targets the receptor-binding site of SARS-CoV-2. Nature 584, 120-124 (2020). doi:10.1038/s41586-020-2381-y Medline

23. S. J. Zost, P. Gilchuk, J. B. Case, E. Binshtein, R. E. Chen, J. P. Nkolola, A. Schäfer, J. X. Reidy, A. Trivette, R. S. Nargi, R. E. Sutton, N. Suryadevara, D. R. Martinez, L. E. Williamson, E. C. Chen, T. Jones, S. Day, L. Myers, A. O. Hassan, N. M. Kafai, E. S. Winkler, J. M. Fox, S. Shrihari, B. K. Mueller, J. Meiler, A. Chandrashekar, N. B. Mercado, J. J. Steinhardt, K. Ren, Y.-M. Loo, N. L. Kallewaard, B. T. McCune, S. P. Keeler, M. J. Holtzman, D. H. Barouch, L. E. Gralinski, R. S. Baric, L. B. Thackray, M. S. Diamond, R. H. Carnahan, J. E. Crowe Jr., Potently neutralizing and protective human antibodies against SARS-CoV-2. Nature 584, 443-449 (2020). doi:10.1038/s41586-020-2548-6 Medline

24. S. J. Zost, P. Gilchuk, R. E. Chen, J. B. Case, J. X. Reidy, A. Trivette, R. S. Nargi, R. E. Sutton, N. Suryadevara, E. C. Chen, E. Binshtein, S. Shrihari, M. Ostrowski, H. Y. Chu, J. E. Didier, K. W. MacRenaris, T. Jones, S. Day, L. Myers, F. Eun-Hyung Lee, D. C. Nguyen, I. Sanz, D. R. Martinez, P. W. Rothlauf, L.-M. Bloyet, S. P. J. Whelan, R. S. Baric, L. B. Thackray, M. S. Diamond, R. H. Carnahan, J. E. Crowe Jr., Rapid isolation and profiling of a diverse panel of human monoclonal antibodies targeting the SARS-CoV-2 spike protein. Nat. Med. 26, 1422-1427 (2020). doi:10.1038/s41591-020-0998-x Medline

25. D. F. Robbiani, C. Gaebler, F. Muecksch, J. C. C. Lorenzi, Z. Wang, A. Cho, M. Agudelo, C. O. Barnes, A. Gazumyan, S. Finkin, T. Hägglöf, T. Y. Oliveira, C. Viant, A. Hurley, H.-H. Hoffmann, K. G. Millard, R. G. Kost, M. Cipolla, K. Gordon, F. Bianchini, S. T. Chen, V. Ramos, R. Patel, J. Dizon, I. Shimeliovich, P. Mendoza, H. Hartweger, L. Nogueira, M. Pack, J. Horowitz, F. Schmidt, Y. Weisblum, E. Michailidis, A. W. Ashbrook, E. Waltari, J. E. Pak, K. E. Huey-Tubman, N. Koranda, P. R. Hoffman, A. P. West Jr., C. M. Rice, T. Hatziioannou, P. J. Bjorkman, P. D. Bieniasz, M. Caskey, M. C. Nussenzweig, Convergent antibody responses to SARS-CoV-2 in convalescent individuals. Nature 584, 437-442 (2020). doi:10.1038/s41586-020-2456-9 Medline

26. T. F. Rogers, F. Zhao, D. Huang, N. Beutler, A. Burns, W. T. He, O. Limbo, C. Smith, G. Song, J. Woehl, L. Yang, R. K. Abbott, S. Callaghan, E. Garcia, J. Hurtado, M Parren, L. Peng, S. Ramirez, J. Ricketts, M. J. Ricciardi, S. A. Rawlings, N. C. Wu, M. Yuan, D. M. Smith, D. Nemazee, J. R. Teijaro, J. E. Voss, I. A. Wilson, R. Andrabi, B. Briney, E. Landais, D. Sok, J. G. Jardine, D. R. Burton, Isolation of potent SARSCoV-2 neutralizing antibodies and protection from disease in a small animal model. Science 369, 956-963 (2020). doi:10.1126/science.abc7520 Medline

27. Y. Cao et al., Potent Neutralizing Antibodies against SARS-CoV-2 Identified by High-Throughput Single-Cell Sequencing of Convalescent Patients' B Cells. Cell 182, $73-84$ e16 (2020)

28. M. Yuan, N. C. Wu, X. Zhu, C. D. Lee, R. T. Y. So, H. Lv, C. K. P. Mok, I. A. Wilson, A highly conserved cryptic epitope in the receptor binding domains of SARS-CoV-2 and SARS-CoV. Science 368, 630-633 (2020). doi:10.1126/science.abb7269 Medline

29. W. Li, A. Drelich, D. R. Martinez, L. Gralinski, C. Chen, Z. Sun, X. Liu, D. Zhelev, L. Zhang, E. C. Peterson, A. Conard, J. W. Mellors, C. T. Tseng, R. S. Baric, D. S. Dimitrov, Potent neutralization of SARS-CoV-2 in vitro and in an animal model by a human monoclonal antibody. bioRxiv 2020.05.13.093088 (2020). Medline

30. A. Z. Wec, D. Wrapp, A. S. Herbert, D. P. Maurer, D. Haslwanter, M. Sakharkar, R K. Jangra, M. E. Dieterle, A. Lilov, D. Huang, L. V. Tse, N. V. Johnson, C.-L. Hsieh, N. Wang, J. H. Nett, E. Champney, I. Burnina, M. Brown, S. Lin, M. Sinclair, C. Johnson, S. Pudi, R. Bortz 3rd, A. S. Wirchnianski, E. Laudermilch, C. Florez, J. M. Fels, C. M. O'Brien, B. S. Graham, D. Nemazee, D. R. Burton, R. S. Baric, J. E. Voss, K. Chandran, J. M. Dye, J. S. McLellan, L. M. Walker, Broad neutralization of SARSrelated viruses by human monoclonal antibodies. Science 369, 731-736 (2020). doi:10.1126/science.abc7424 Medline

31. B. Ju, Q. Zhang, J. Ge, R. Wang, J. Sun, X. Ge, J. Yu, S. Shan, B. Zhou, S. Song, X. Tang, J. Yu, J. Lan, J. Yuan, H. Wang, J. Zhao, S. Zhang, Y. Wang, X. Shi, L. Liu, J. Zhao, X. Wang, Z. Zhang, L. Zhang, Human neutralizing antibodies elicited by SARS-CoV-2 infection. Nature 584, 115-119 (2020). doi:10.1038/s41586-0202380-z Medline

32. Y. Wu, F. Wang, C. Shen, W. Peng, D. Li, C. Zhao, Z. Li, S. Li, Y. Bi, Y. Yang, Y. Gong H. Xiao, Z. Fan, S. Tan, G. Wu, W. Tan, X. Lu, C. Fan, Q. Wang, Y. Liu, C. Zhang, J. Qi, G. F. Gao, F. Gao, L. Liu, A noncompeting pair of human neutralizing antibodies block COVID-19 virus binding to its receptor ACE2. Science 368, 1274-1278 (2020). doi:10.1126/science.abc2241 Medline

33. E. Seydoux et al., Analysis of a SARS-CoV-2-Infected Individual Reveals Development of Potent Neutralizing Antibodies with Limited Somatic Mutation. Immunity 53, 98-105 e105 (2020).

34. C. O. Barnes et al., Structures of Human Antibodies Bound to SARS-CoV-2 Spike Reveal Common Epitopes and Recurrent Features of Antibodies. Cell 182, 828842 e816 (2020).

35. A. Rambaut et al., Preliminary genomic characterisation of an emergent SARSCoV-2 lineage in the UK defined by a novel set of spike mutations. https://virological.org/t/preliminary-genomic-characterisation-of-anemergent-sars-cov-2-lineage-in-the-uk-defined-by-a-novel-set-of-spike- 
mutations/563 (2020).

36. H. Tegally et al., Emergence and rapid spread of a new severe acute respiratory syndrome-related coronavirus 2 (SARS-CoV-2) lineage with multiple spike mutations in South Africa. medRxiv, 2020.2012.2021.20248640 (2020).

37. R. N. Faria et al., Genomic characterisation of an emergent SARS-CoV-2 lineage in Manaus: preliminary findings. https://virological.org/t/genomiccharacterisation-of-an-emergent-sars-cov-2-lineage-in-manaus-preliminaryfindings/586 (2020).

38. C. M. Voloch et al., Genomic characterization of a novel SARS-CoV-2 lineage from Rio de Janeiro, Brazil. medRxiv, 2020.2012.2023.20248598 (2020).

39. F. Naveca et al., Phylogenetic relationship of SARS-CoV-2 sequences from Amazonas with emerging Brazilian variants harboring mutations E484K and N501Y in the Spike protein. https://virological.org/t/phylogenetic-relationshipof-sars-cov-2-sequences-from-amazonas-with-emerging-brazilian-variantsharboring-mutations-e484k-and-n501y-in-the-spike-protein/585 (2020)

40. E. Andreano et al., SARS-CoV-2 escape <em>in vitro</em> from a highly neutralizing COVID-19 convalescent plasma. bioRxiv, 2020.2012.2028.424451 (2020).

41. Y. Weisblum, F. Schmidt, F. Zhang, J. DaSilva, D. Poston, J. C. C. Lorenzi, F. Muecksch, M. Rutkowska, H.-H. Hoffmann, E. Michailidis, C. Gaebler, M. Agudelo, A. Cho, Z. Wang, A. Gazumyan, M. Cipolla, L. Luchsinger, C. D. Hillyer, M. Caskey, D. F. Robbiani, C. M. Rice, M. C. Nussenzweig, T. Hatziioannou, P. D. Bieniasz, Escape from neutralizing antibodies by SARS-CoV-2 spike protein variants. bioRxiv 9, e61312 (2020). doi:10.7554/eLife.61312 Medline

42. Q. Li et al., The Impact of Mutations in SARS-CoV-2 Spike on Viral Infectivity and Antigenicity. Cell 182, 1284-1294 e1289 (2020).

43. A. J. Greaney et al., Comprehensive mapping of mutations to the SARS-CoV-2 receptor-binding domain that affect recognition by polyclonal human serum antibodies. bioRxiv, 2020.2012.2031.425021 (2021).

44. D. Pinto, Y.-J. Park, M. Beltramello, A. C. Walls, M. A. Tortorici, S. Bianchi, S. Jaconi, K. Culap, F. Zatta, A. De Marco, A. Peter, B. Guarino, R. Spreafico, E. Cameroni, J. B. Case, R. E. Chen, C. Havenar-Daughton, G. Snell, A. Telenti, H. W. Virgin, A. Lanzavecchia, M. S. Diamond, K. Fink, D. Veesler, D. Corti, Cross-neutralization of SARS-CoV-2 by a human monoclonal SARS-CoV antibody. Nature 583, 290-295 (2020). doi:10.1038/s41586-020-2349-y Medline

45. D. Zhou, H. M. E. Duyvesteyn, C.-P. Chen, C.-G. Huang, T.-H. Chen, S.-R. Shih, Y.C. Lin, C.-Y. Cheng, S.-H. Cheng, Y.-C. Huang, T.-Y. Lin, C. Ma, J. Huo, L. Carrique, T. Malinauskas, R. R. Ruza, P. N. M. Shah, T. K. Tan, P. Rijal, R. F. Donat, K. Godwin, K. R. Buttigieg, J. A. Tree, J. Radecke, N. G. Paterson, P. Supasa, J. Mongkolsapaya, G. R. Screaton, M. W. Carroll, J. Gilbert-Jaramillo, M. L. Knight, W. James, R. J. Owens, J. H. Naismith, A. R. Townsend, E. E. Fry, Y. Zhao, J. Ren, D. I. Stuart, K. A. Huang, Structural basis for the neutralization of SARS-CoV-2 by an antibody from a convalescent patient. Nat. Struct. Mol. Biol. 27, 950-958 (2020). doi:10.1038/s41594-020-0480-y Medline

46. H. Liu, N. C. Wu, M. Yuan, S. Bangaru, J. L. Torres, T. G. Caniels, J. van Schooten, X. Zhu, C. D. Lee, P. J. M. Brouwer, M. J. van Gils, R. W. Sanders, A. B. Ward, I. A. Wilson, Cross-neutralization of a SARS-CoV-2 antibody to a functionally conserved site is mediated by avidity. bioRxiv 2020.08.02.233536 (2020). Medline

47. Z. Lv, Y.-Q. Deng, Q. Ye, L. Cao, C.-Y. Sun, C. Fan, W. Huang, S. Sun, Y. Sun, L. Zhu, Q. Chen, N. Wang, J. Nie, Z. Cui, D. Zhu, N. Shaw, X.-F. Li, Q. Li, L. Xie, Y. Wang, Z. Rao, C.-F. Qin, X. Wang, Structural basis for neutralization of SARS-CoV-2 and SARS-CoV by a potent therapeutic antibody. Science 369, 1505-1509 (2020). doi:10.1126/science.abc5881 Medline

48. X. Chi, R. Yan, J. Zhang, G. Zhang, Y. Zhang, M. Hao, Z. Zhang, P. Fan, Y. Dong, Y. Yang, Z. Chen, Y. Guo, J. Zhang, Y. Li, X. Song, Y. Chen, L. Xia, L. Fu, L. Hou, J. Xu, C. Yu, J. Li, O. Zhou, W. Chen, A neutralizing human antibody binds to the $\mathrm{N}$ terminal domain of the Spike protein of SARS-CoV-2. Science 369, 650-655 (2020). doi:10.1126/science.abc6952 Medline

49. H. Liu et al., Cross-Neutralization of a SARS-CoV-2 Antibody to a Functionally Conserved Site Is Mediated by Avidity. Immunity 53, 1272-1280 e1275 (2020).

50. H. Lv, N. C. Wu, O. T.-Y. Tsang, M. Yuan, R. A. P. M. Perera, W. S. Leung, R. T. Y. So, J. M. C. Chan, G. K. Yip, T. S. H. Chik, Y. Wang, C. Y. C. Choi, Y. Lin, W. W. Ng, J. Zhao, L. L. M. Poon, J. S. M. Peiris, I. A. Wilson, C. K. P. Mok, Cross-reactive Antibody Response between SARS-CoV-2 and SARS-CoV Infections. Cell Rep. 31,
107725 (2020). doi:10.1016/i.celrep.2020.107725

51. B. R. West, C. L. Moyer, L. B. King, M. L. Fusco, J. C. Milligan, S. Hui, E. O. Saphire, Structural Basis of Pan-Ebolavirus Neutralization by a Human Antibody against a Conserved, yet Cryptic Epitope. mBio 9, e01674-18 (2018). doi:10.1128/mBio.01674-18 Medline

52. C. Wang, W. Li, D. Drabek, N. M. A. Okba, R. van Haperen, A. D. M. E. Osterhaus, F. J. M. van Kuppeveld, B. L. Haagmans, F. Grosveld, B.-J. Bosch, A human monoclonal antibody blocking SARS-CoV-2 infection. Nat. Commun. 11, 2251 (2020). doi:10.1038/s41467-020-16256-y Medline

53. B. L. Haagmans et al., SARS-CoV-2 neutralizing human antibodies protect against lower respiratory tract disease in a hamster model. bioRxiv, 2020.2008.2024.264630 (2020).

54. S. K. Wong, W. Li, M. J. Moore, H. Choe, M. Farzan, A 193-amino acid fragment of the SARS coronavirus $S$ protein efficiently binds angiotensin-converting enzyme 2. J. Biol. Chem. 279, 3197-3201 (2004). doi:10.1074/ibc.C300520200 Medline

55. M. Gur, E. Taka, S. Z. Yilmaz, C. Kilinc, U. Aktas, M. Golcuk, Conformational transition of SARS-CoV-2 spike glycoprotein between its closed and open states. J. Chem. Phys. 153, 075101 (2020). doi:10.1063/5.0011141 Medline

56. J. Huo et al., Neutralization of SARS-CoV-2 by Destruction of the Prefusion Spike. Cell Host Microbe 28, 445-454 e446 (2020).

57. C. Toelzer, K. Gupta, S. K. N. Yadav, U. Borucu, A. D. Davidson, M. Kavanagh Williamson, D. K. Shoemark, F. Garzoni, O. Staufer, R. Milligan, J. Capin, A. J. Mulholland, J. Spatz, D. Fitzgerald, I. Berger, C. Schaffitzel, Free fatty acid binding pocket in the locked structure of SARS-CoV-2 spike protein. Science 370, 725730 (2020). doi:10.1126/science.abd3255 Medline

58. T. Koyama, D. Platt, L. Parida, Variant analysis of SARS-CoV-2 genomes. Bull. World Health Organ. 98, 495-504 (2020). doi:10.2471/BLI20.253591 Medline

59. T. N. Starr et al., Deep Mutational Scanning of SARS-CoV-2 Receptor Binding Domain Reveals Constraints on Folding and ACE2 Binding. Cell 182, 1295-1310 el220 (2020)

60. D. Wrapp, D. De Vlieger, K. S. Corbett, G. M. Torres, N. Wang, W. Van Breedam, K. Roose, L. van Schie, M. Hoffmann, S. Pöhlmann, B. S. Graham, N. Callewaert, B. Schepens, X. Saelens, J. S. McLellan; VIB-CMB COVID-19 Response Team, Structural Basis for Potent Neutralization of Betacoronaviruses by Single-Domain Camelid Antibodies. Cell 181, 1436-1441 (2020). doi:10.1016/i.cell.2020.05.047 Medline

61. C. O. Barnes, C. A. Jette, M. E. Abernathy, K. A. Dam, S. R. Esswein, H. B. Gristick, A. G. Malyutin, N. G. Sharaf, K. E. Huey-Tubman, Y. E. Lee, D. F. Robbiani, M. C. Nussenzweig, A. P. West Jr., P. J. Bjorkman, SARS-CoV-2 neutralizing antibody structures inform therapeutic strategies. Nature 588, 682-687 (2020). doi:10.1038/s41586-020-2852-1 Medline

62. M. A. Tortorici, M. Beltramello, F. A. Lempp, D. Pinto, H. V. Dang, L. E. Rosen, M. McCallum, J. Bowen, A. Minola, S. Jaconi, F. Zatta, A. De Marco, B. Guarino, S. Bianchi, E. J. Lauron, H. Tucker, J. Zhou, A. Peter, C. Havenar-Daughton, J. A. Wojcechowskyj, J. B. Case, R. E. Chen, H. Kaiser, M. Montiel-Ruiz, M. Meury, N. Czudnochowski, R. Spreafico, J. Dillen, C. Ng, N. Sprugasci, K. Culap, F. Benigni, R. Abdelnabi, S. C. Foo, M. A. Schmid, E. Cameroni, A. Riva, A. Gabrieli, M. Galli, M. S. Pizzuto, J. Neyts, M. S. Diamond, H. W. Virgin, G. Snell, D. Corti, K. Fink, D. Veesler, Ultrapotent human antibodies protect against SARS-CoV-2 challenge via multiple mechanisms. Science 370, 950-957 (2020). doi:10.1126/science.abe3354 Medline

63. H. L. Wells, M. Letko, G. Lasso, B. Ssebide, J. Nziza, D. K. Byarugaba, I. NavarreteMacias, E. Liang, M. Cranfield, B. A. Han, M. W. Tingley, M. Diuk-Wasser, T. Goldstein, C. K. Johnson, J. Mazet, K. Chandran, V. J. Munster, K. Gilardi, S. J. Anthony, The evolutionary history of ACE2 usage within the coronavirus subgenus Sarbecovirus. bioRxiv 2020.07.07.190546 (2020). Medline

64. C. Huang, J. Qi, G. Lu, Q. Wang, Y. Yuan, Y. Wu, Y. Zhang, J. Yan, G. F. Gao, Putative Receptor Binding Domain of Bat-Derived Coronavirus HKU9 Spike Protein: Evolution of Betacoronavirus Receptor Binding Motifs. Biochemistry 55, 59775988 (2016). doi:10.1021/acs.biochem.6b00790 Medline

65. X. L. Yang, B. Hu, B. Wang, M.-N. Wang, Q. Zhang, W. Zhang, L.-J. Wu, X.-Y. Ge, Y.Z. Zhang, P. Daszak, L.-F. Wang, Z.-L. Shi, Isolation and Characterization of a Novel Bat Coronavirus Closely Related to the Direct Progenitor of Severe Acute Respiratory Syndrome Coronavirus. J. Virol. 90, 3253-3256 (2015) doi:10.1128/JVl.02582-15 Medline 
66. A. H. M. Wong, A. C. A. Tomlinson, D. Zhou, M. Satkunarajah, K. Chen, C. Sharon, M. Desforges, P. J. Talbot, J. M. Rini, Receptor-binding loops in alphacoronavirus adaptation and evolution. Nat. Commun. 8, 1735 (2017). doi:10.1038/s41467-01701706-x $\underline{\text { Medline }}$

67. M. Schorb, I. Haberbosch, W. J. H. Hagen, Y. Schwab, D. N. Mastronarde, Software tools for automated transmission electron microscopy. Nat. Methods 16, 471-477 (2019). doi:10.1038/s41592-019-0396-9 Medline

68. J. Zivanov, T. Nakane, S. H. W. Scheres, A Bayesian approach to beam-induced motion correction in cryo-EM single-particle analysis. IUCrJ 6, 5-17 (2019). doi:10.1107/S205225251801463X Medline

69. S. Q. Zheng, E. Palovcak, J.-P. Armache, K. A. Verba, Y. Cheng, D. A. Agard, MotionCor2: Anisotropic correction of beam-induced motion for improved cryoelectron microscopy. Nat. Methods 14, 331-332 (2017). doi:10.1038/nmeth.4193 Medline

70. A. Rohou, N. Grigorieff, CTFFIND4: Fast and accurate defocus estimation from electron micrographs. J. Struct. Biol. 192, 216-221 (2015). doi:10.1016/j.jsb.2015.08.008 Medline

71. E. F. Pettersen, T. D. Goddard, C. C. Huang, G. S. Couch, D. M. Greenblatt, E. C. Meng, T. E. Ferrin, UCSF Chimera-A visualization system for exploratory research and analysis. J. Comput. Chem. 25, 1605-1612 (2004). doi:10.1002/jcc.20084 Medline

72. P. Emsley, K. Cowtan, Coot: Model-building tools for molecular graphics. Acta $\begin{array}{lllll}\text { Crystallogr. D Biol. Crystallogr. 60, 2126-2132 (2004). } & \end{array}$ doi:10.1107/S0907444904019158 Medline

73. A. C. Walls et al., Unexpected Receptor Functional Mimicry Elucidates Activation of Coronavirus Fusion. Cell 176, 1026-1039 e1015 (2019).

74. Q. Wang, T. Ma, Y. Wu, Z. Chen, H. Zeng, Z. Tong, F. Gao, J. Qi, Z. Zhao, Y. Chai, H. Yang, G. Wong, Y. Bi, L. Wu, R. Shi, M. Yang, J. Song, H. Jiang, Z. An, J. Wang, T. D. Yilma, Y. Shi, W. J. Liu, M. Liang, C. Qin, G. F. Gao, J. Yan, Neutralization mechanism of human monoclonal antibodies against Rift Valley fever virus. Nat. Microbiol. 4, 1231-1241 (2019). doi:10.1038/s41564-019-0411-z Medline

75. A. Cassotta, V. Mikol, T. Bertrand, S. Pouzieux, J. Le Parc, P. Ferrari, J. Dumas, M. Auer, F. Deisenhammer, M. Gastaldi, D. Franciotta, C. Silacci-Fregni, B. Fernandez Rodriguez, I. Giacchetto-Sasselli, M. Foglierini, D. Jarrossay, R. Geiger, F. Sallusto, A. Lanzavecchia, L. Piccoli, A single T cell epitope drives the neutralizing anti-drug antibody response to natalizumab in multiple sclerosis patients. Nat. Med. 25 1402-1407 (2019). doi:10.1038/s41591-019-0568-2 Medline

76. G. Bunkóczi, R. J. Read, Improvement of molecular-replacement models with Sculptor. Acta Crystallogr. D Biol. Crystallogr. 67, 303-312 (2011). doi:10.1107/S0907444910051218 Medline

77. J. J. Headd, N. Echols, P. V. Afonine, R. W. Grosse-Kunstleve, V. B. Chen, N. W. Moriarty, D. C. Richardson, J. S. Richardson, P. D. Adams, Use of knowledge-based restraints in phenix.refine to improve macromolecular refinement at low resolution. Acta Crystallogr. D Biol. Crystallogr. 68, 381-390 (2012). doi:10.1107/S0907444911047834 Medline

78. T. I. Croll, ISOLDE: A physically realistic environment for model building into lowresolution electron-density maps. Acta Crystallogr. D Struct. Biol. 74, 519-530 (2018). doi:10.1107/S2059798318002425 Medline

79. V. B. Chen, W. B. Arendall 3rd, J. J. Headd, D. A. Keedy, R. M. Immormino, G. J. Kapral, L. W. Murray, J. S. Richardson, D. C. Richardson, MolProbity: All-atom structure validation for macromolecular crystallography. Acta Crystallogr. D Biol. Crystallogr. 66, 12-21 (2010). doi:10.1107/S0907444909042073 Medline

80. J. Agirre, J. Iglesias-Fernández, C. Rovira, G. J. Davies, K. S. Wilson, K. D. Cowtan, Privateer: Software for the conformational validation of carbohydrate structures. Nat. Struct. Mol. Biol. 22, 833-834 (2015). doi:10.1038/nsmb.3115 Medline

81. J. Agirre, G. Davies, K. Wilson, K. Cowtan, Carbohydrate anomalies in the PDB. Nat. Chem. Biol. 11, 303 (2015). doi:10.1038/nchembio.1798 Medline

82. E. Krissinel, K. Henrick, Inference of macromolecular assemblies from crystalline state. J. Mol. Biol. 372, 774-797 (2007). doi:10.1016/i.jmb.2007.05.022 Medline

83. W. Tian, C. Chen, X. Lei, J. Zhao, J. Liang, CASTp 3.0: Computed atlas of surface topography of proteins. Nucleic Acids Res. 46 (W1), W363-W367 (2018). doi:10.1093/nar/gky473 Medline

84. T. D. Goddard, C. C. Huang, E. C. Meng, E. F. Pettersen, G. S. Couch, J. H. Morris, T. E. Ferrin, UCSF ChimeraX: Meeting modern challenges in visualization and analysis. Protein Sci. 27, 14-25 (2018). doi:10.1002/pro.3235 Medline
85. F. Madeira, Y. M. Park, J. Lee, N. Buso, T. Gur, N. Madhusoodanan, P. Basutkar, A. R. N. Tivey, S. C. Potter, R. D. Finn, R. Lopez, The EMBL-EBI search and sequence analysis tools APIs in 2019. Nucleic Acids Res. 47 (W1), W636-W641 (2019). doi:10.1093/nar/gkz268 Medline

86. X. Robert, P. Gouet, Deciphering key features in protein structures with the new ENDscript server. Nucleic Acids Res. 42 (W1), W320-W324 (2014). doi:10.1093/nar/gku316 Medline

\section{ACKNOWLEDGMENTS}

We thank F.A. Rey for his valuable comments on the manuscript. This work was supported by the European Research Council under the European Union's Horizon2020 Programme (ERC Consolidator Grant Agreement 724425 BENDER). J.F. and D.L.H. are funded from the European Union's Horizon 2020 research and innovation program under the Marie Skłodowska-Curie grant agreement (No 792575 and 842333). J.F. and D.L.H. also hold EMBO nonstipendiary long-term Fellowships (ALTF 948-2017 and ALTF 1172-2018). Research reported in this publication was supported by a China Scholarship Council grant to C.W. (CSC201708620178). S.C.H. was funded through the Utrecht Molecular Immunology Hub (Utrecht University). We thank Dr Mihajlo Vanevic for IT support. Author contributions: J.F., D.L.H., C.W., W.L., F.J.M.K., F.F. and B.J.B. conceived, designed, and coordinated the study. J.F., D.L.H., C.W., W.L., I.D., G.O., W.D., and S.C.H. conducted the experiments. F.J.M.K, F.F. and B.J.B. supervised part of the experiments. All authors contributed to the interpretations and conclusions presented. J.F. D.L.H. and B.J.B. wrote the manuscript, J.F., D.L.H, C.W., W.L. G.O., F.F. and B.J.B. participated in editing the manuscript. Competing interests: A patent application has been filed on 12 March 2020 on monoclonal antibodies targeting SARS-CoV-2 (United Kingdom patent application no. 2003632.3; patent applicants: Utrecht University, Erasmus Medical Center and Harbour BioMed). Utrecht University is party to an exclusive license agreement with AbbVie for the use of 47D11 for the prevention and treatment of COVID-19 and related coronaviruses, for which Utrecht University receives payments from AbbVie. I.D. is an employee of Thermo Fisher Scientific. The other authors declare no competing interests. Data availability: Coordinates for the 47D11-bound SARS-CoV and SARS-CoV-2 spike proteins are deposited in the Protein Data Bank under accession codes 7AKJ and 7AKD, respectively. The corresponding EM density maps have been deposited to the Electron Microscopy Data Bank under the accessions EMD-11813 and EMD11812. Sequences of the 47D11 antibody heavy and light chain have been deposited in GenBank under the accession numbers MW881223 and MW881224. All data needed to evaluate the conclusions in the paper are present in the paper and/or the Supplementary Materials. All data needed to evaluate the conclusions in the paper are present in the paper and/or the Supplementary Materials.

\section{SUPPLEMENTARY MATERIALS}

advances.sciencemag.org/cgi/content/full/sciadv.abf5632/DC1

Submitted 3 November 2020

Accepted 26 March 2021

Published First Release 6 May 2021

$10.1126 /$ sciadv.abf5632 


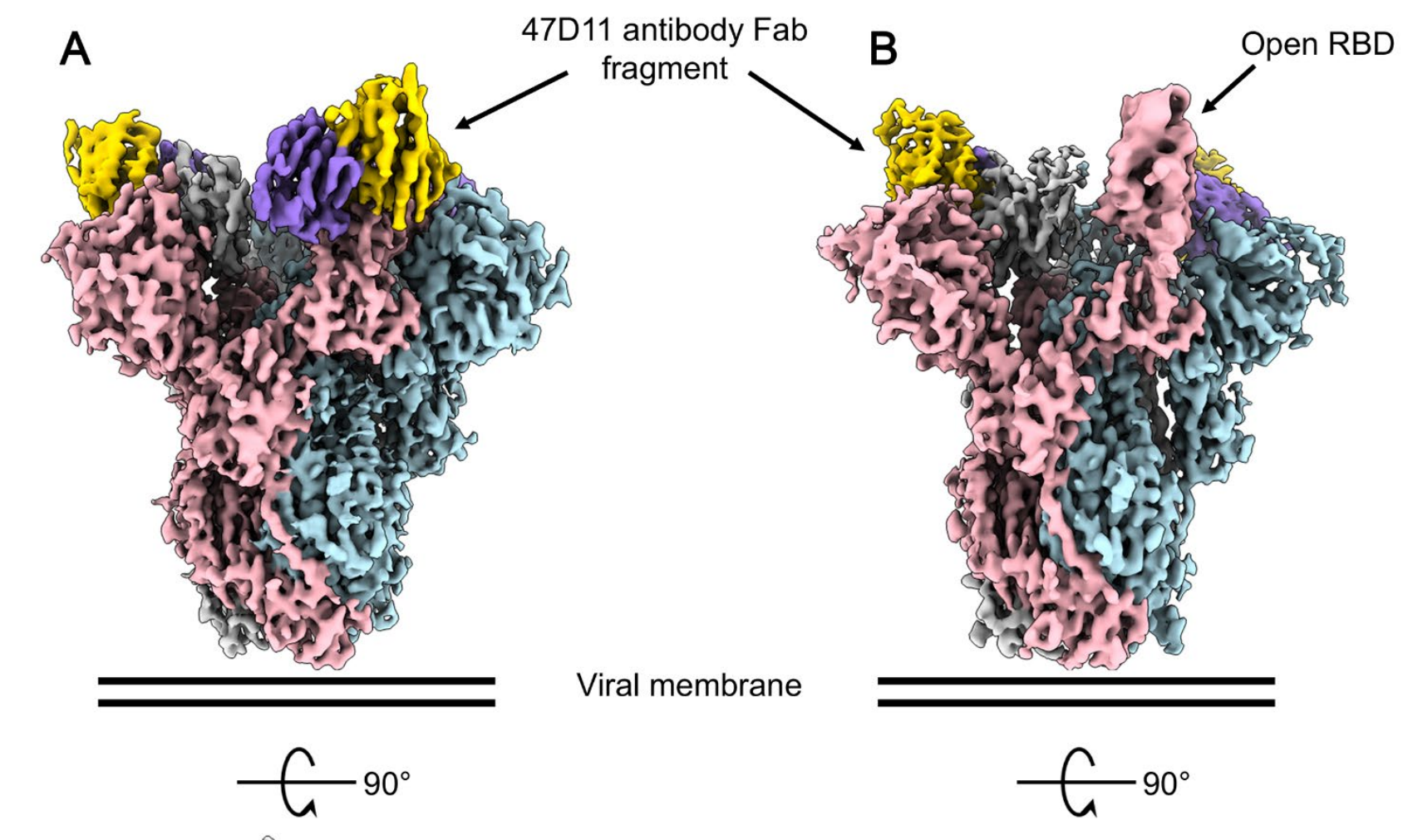

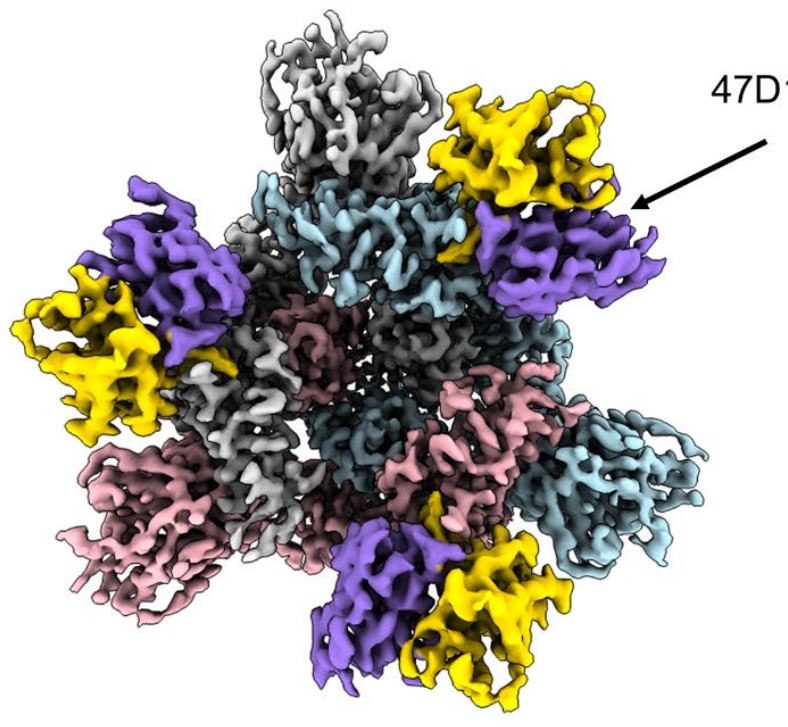

Closed SARS-CoV S trimer

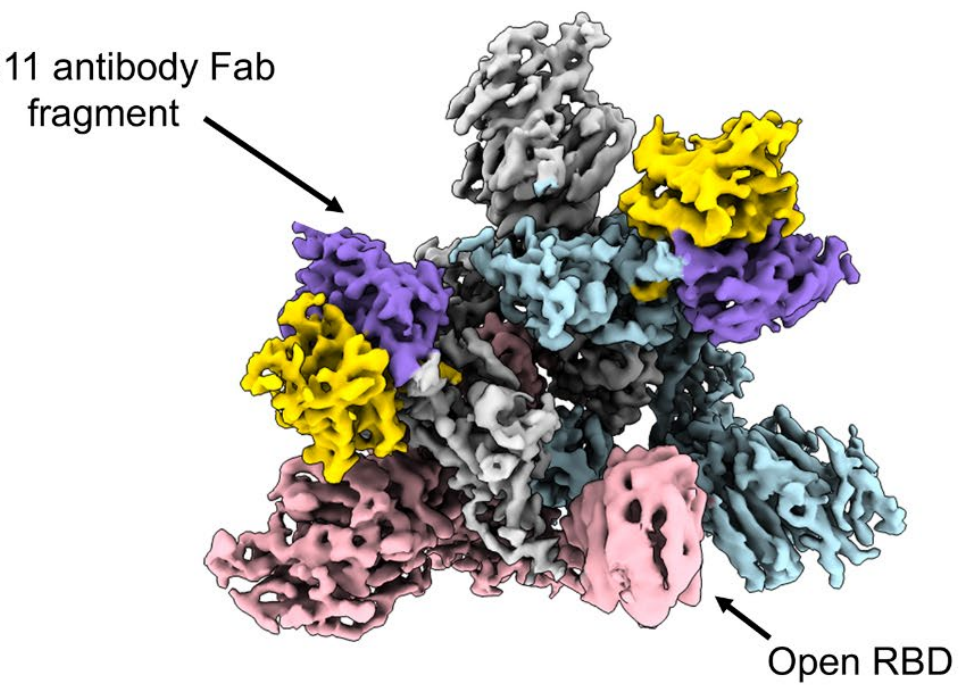

Partially open SARS-CoV-2 S trimer

Fig. 1. 47D11 has differing conformational selectivity for the SARS-CoV and SARS-CoV-2 spike. A) Surface rendering of the fully closed SARS spike bound to three 47D11 antibody Fab fragments, shown as two orthogonal views. (B) Surface rendering of the partially open SARS2 spike in complex with two 47D11 antibody Fab fragments, shown as two orthogonal views. The spike protomers are colored pink, blue and grey, and the 47D11 heavy and light chain are colored yellow and purple, respectively. For clarity, only the Fab variable region is shown. 

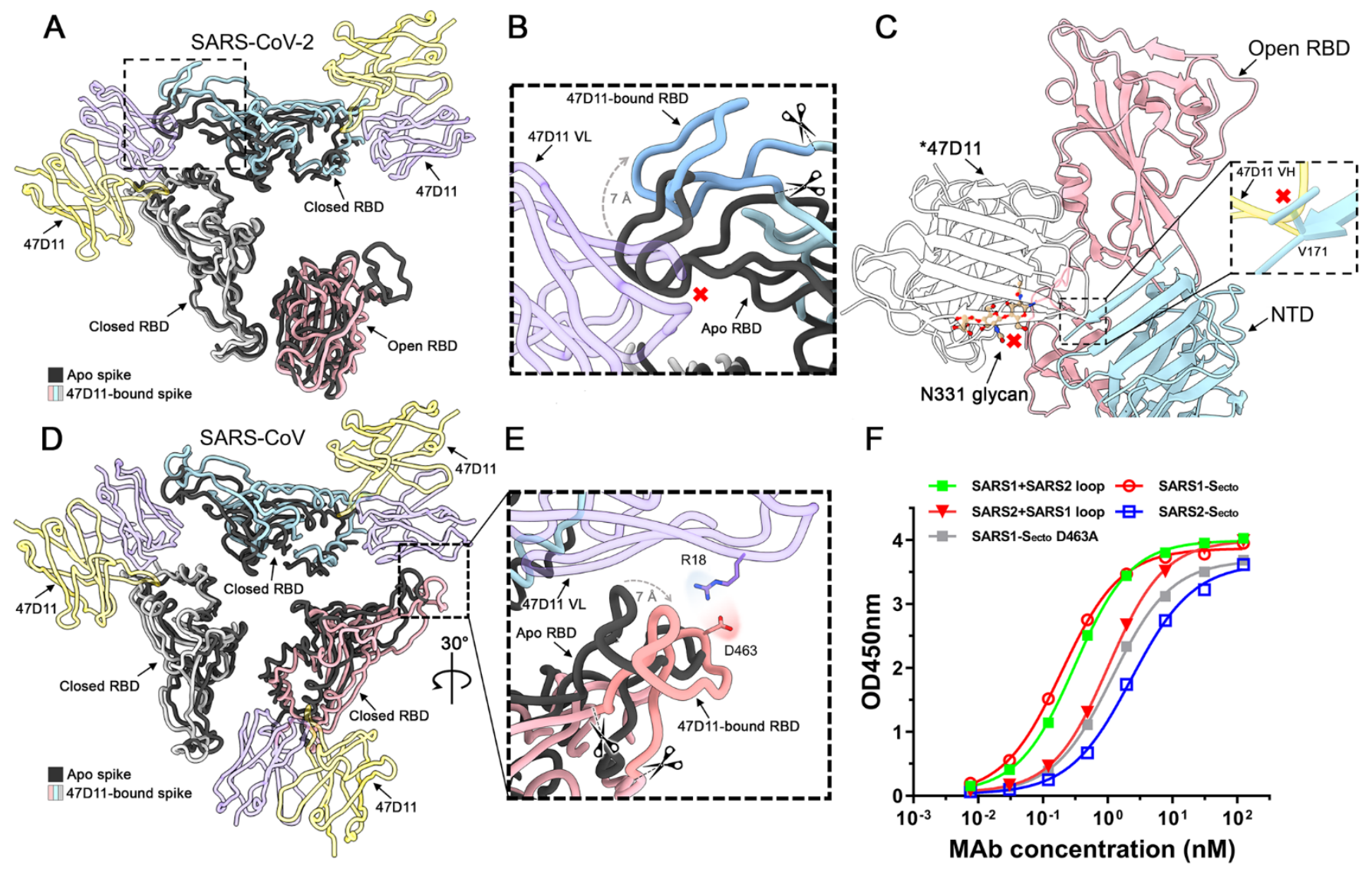

$\mathrm{F}$

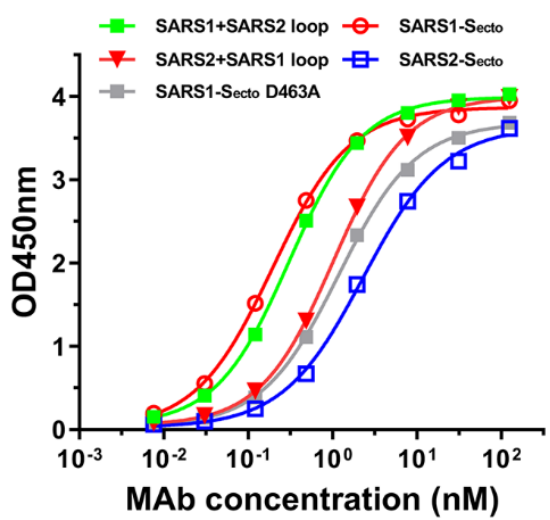

Fig. 2. 47D11 binds specifically to the RBD in down conformation and prevents their full compaction. A) Top view of the 47D11 bound SARS2 spike, shown as a ribbon diagram. The 47D11-bound spike protomers are colored pink, blue and grey, and the 47D11 heavy and light chain are shown semi-transparent and colored yellow and purple, respectively. Glycans, and the N-terminal domain, are omitted for clarity and only the Fab variable region is shown. The superposed structure of the partially open apo SARS2 spike (PDB ID: 6ZGG) is colored black. B) Zoomed in view of the boxed region in panel A. The region encompassing residues 470490, used for the loop swap experiments, is indicated with scissors. C) Zoomed in view of the SARS2 "up" RBD and adjacent NTD, shown in cartoon representation. The overlaid 47D11 Fab is shown as a silhouette and the N343 glycan is shown in ball-and-stick representation and colored tan. The inset panel shows a zoomed in view of the clash between the NTD residue V171 and the 47D11 heavy chain. D) Top view of the 47D11 bound SARS spike colored as shown in panel $A$. The superposed structure of the closed apo SARS spike (PDB ID: 5XLR) is colored black. E) Zoomed in view of the boxed region in panel D, showing a putative salt bridge between the 47D11 variable light chain and the RBD loop. The region encompassing residues 457477, used for the loop swap experiments, is indicated with scissors. F) ELISA-binding curves of 47D11 binding to wildtype, loop swapped and D463A spike ectodomains. 


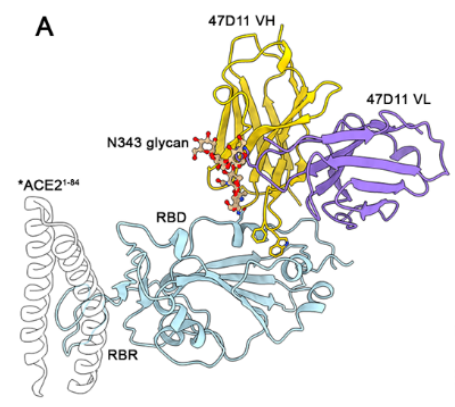

E

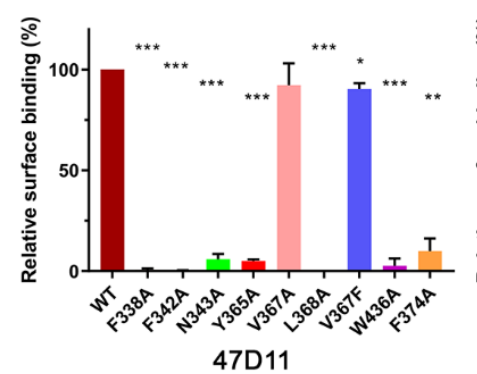

47D11

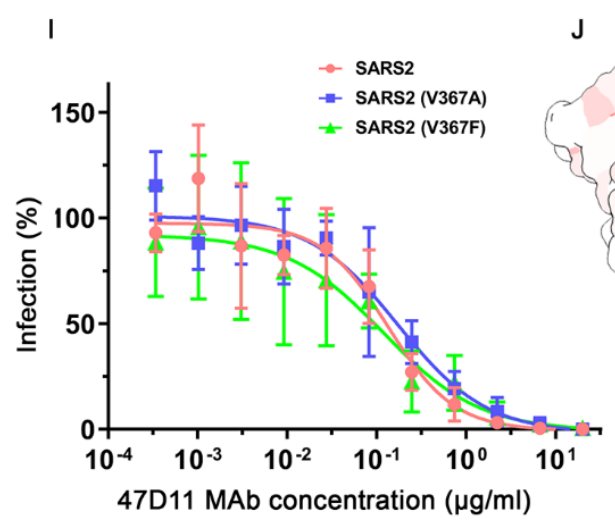

47D11 MAb concentration $(\mu \mathrm{g} / \mathrm{ml})$

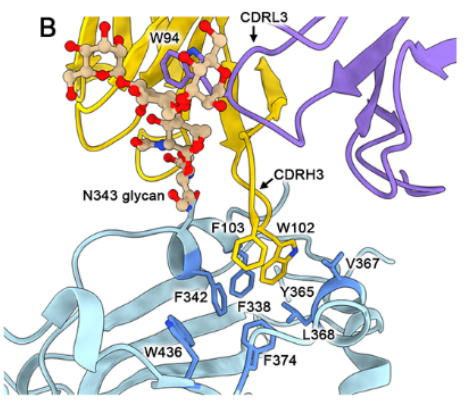

$\mathrm{F}$

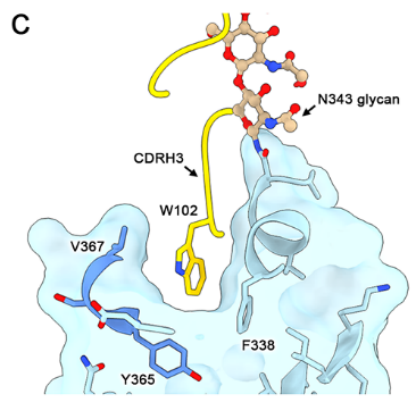

47D11-bound RBD

D

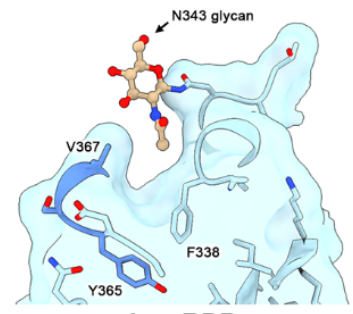

Apo RBD

$\mathrm{H}$

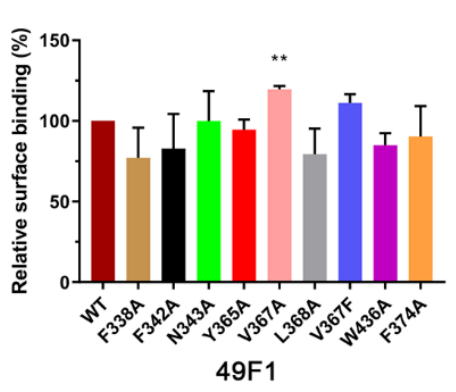

CR3022

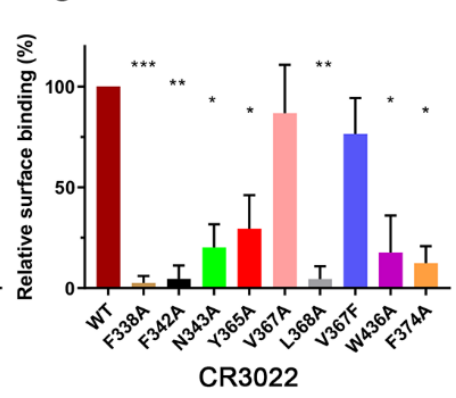

ACE2
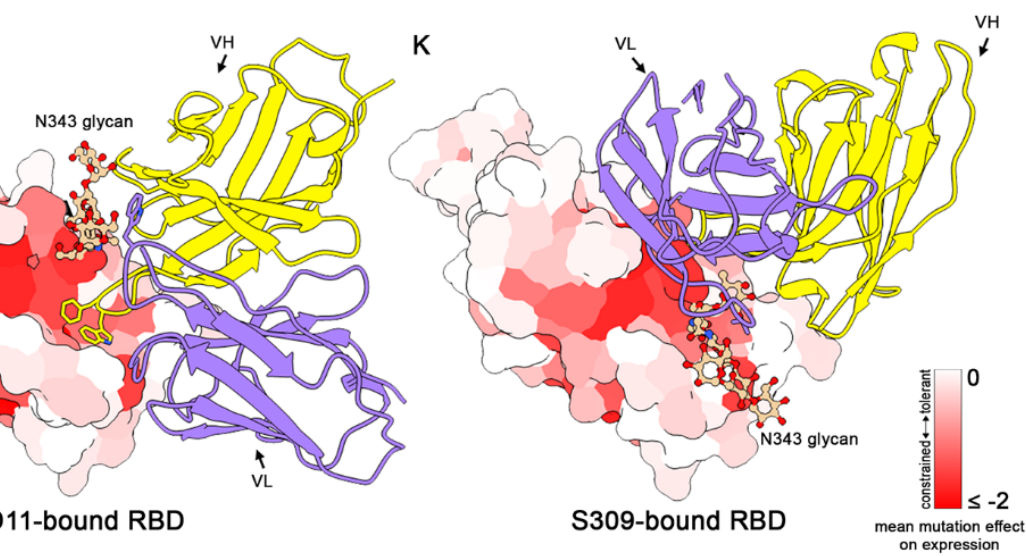

Fig. 3. The 47D11 epitope comprises a mutationally constrained hydrophobic pocket which is normally shielded by glycan N343. A) Ribbon diagram of the SARS2-S receptor-binding domain (RBD) in complex with the 47D11 antibody Fab fragment. For comparison, residues 1-84 of the RBD bound ACE2 (PDB ID: 6MOJ) are shown as a silhouette. B) Close-up view of the 47D11 epitope with the hydrophobic pocket residues shown as sticks and colored dark blue. The N343 glycan is shown in ball-and-stick representation and colored tan. For clarity, only the core pentasaccharide is shown. C) Slice through the surface rendered 47D11 bound SARS2-S RBD. The helix encompassing residues 365-370 is shown in darker blue. D) Equivalent view as shown in panel $C$ for the apo RBD (PDB ID:6VYB). E) Relative binding of 47D11, (F) ACE2 and (G) CR3022 to cell surface expressed SARS2-S, determined by fluorescence-activated cell sorting. $(H)$ Relative binding of an anti-FLAG antibody to permeabilized cells expressing the full-length SARS2 spike epitope mutants, determined by fluorescence-activated cell sorting. The data were analyzed by the unpaired, two-tailed, Student's t test using GraphPad Prism 7.0. A P value $<0.05$ was considered significant ( ${ }^{*} P<0.05$, ${ }^{*} P<0.01$, $\left.{ }^{* *} P<0.0001\right)$. I) Antibody-mediated neutralization of infection of luciferase-encoding VSV particles pseudotyped with wild-type, V367A or V367F SARS2-S. J) Surface representation of the 47D11 bound SARS2-S RBD colored according to mean mutation effect on expression (red indicates more constrained) (59). The Fab is shown as a ribbon diagram. K) As shown in E for the S309 bound SARS2 RBD. 
A

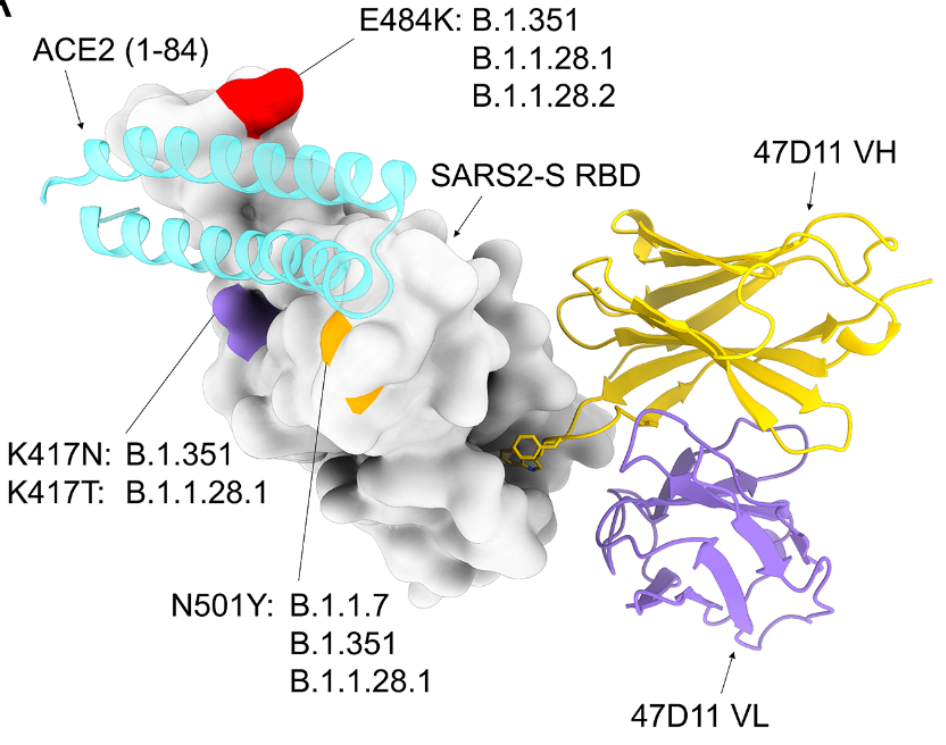

B

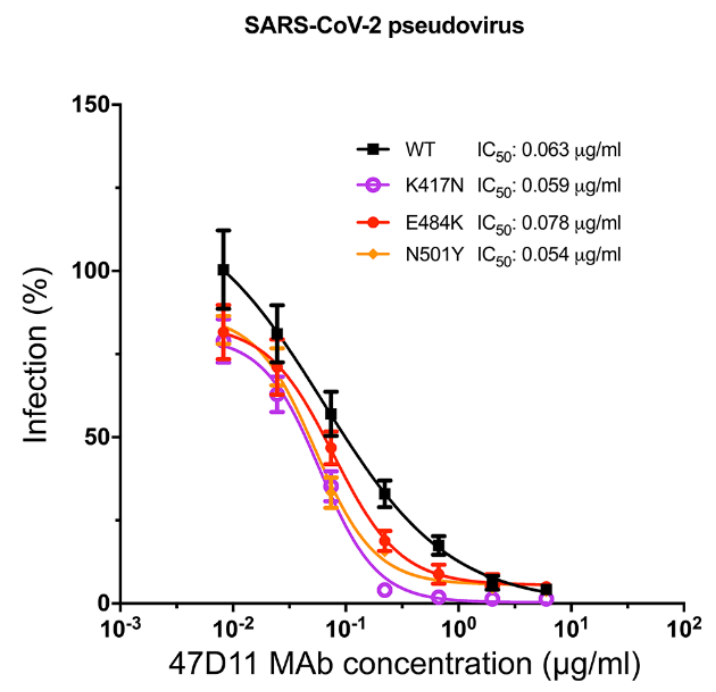

Fig. 4. 47D11 neutralizes SARS2-S pseudoviruses containing single mutations found in the RBM of recently emerged SARS-CoV-2 variants. A) Surface representation of the 47D11-bound RBD with the location of the K417N/T, E484K and N501Y mutations from SARS-CoV-2 variants colored purple, red and orange, respectively, and annotated (35-39). The 47D11 Fab variable chains are shown as a ribbon diagram and the heavy and light chain are colored yellow and purple, respectively. Residues 1-84 of the RBD-bound ACE2 (PDB ID: 6MOJ) are shown for comparison and colored cyan. B) 47D11-mediated neutralization of infection of luciferase-encoding VSV particles pseudotyped with SARS-CoV-2 S containing single RBM mutations. The average \pm SD from two independent experiments with technical triplicates is shown. 


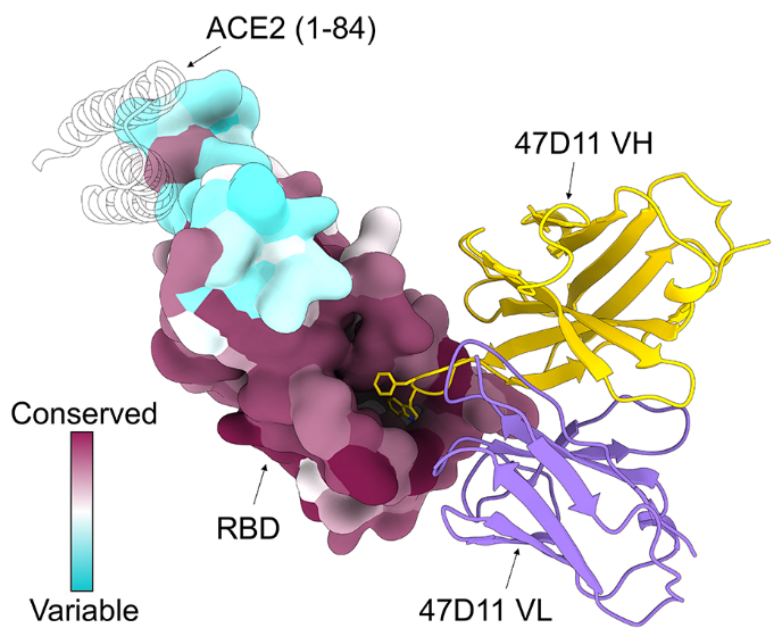

C
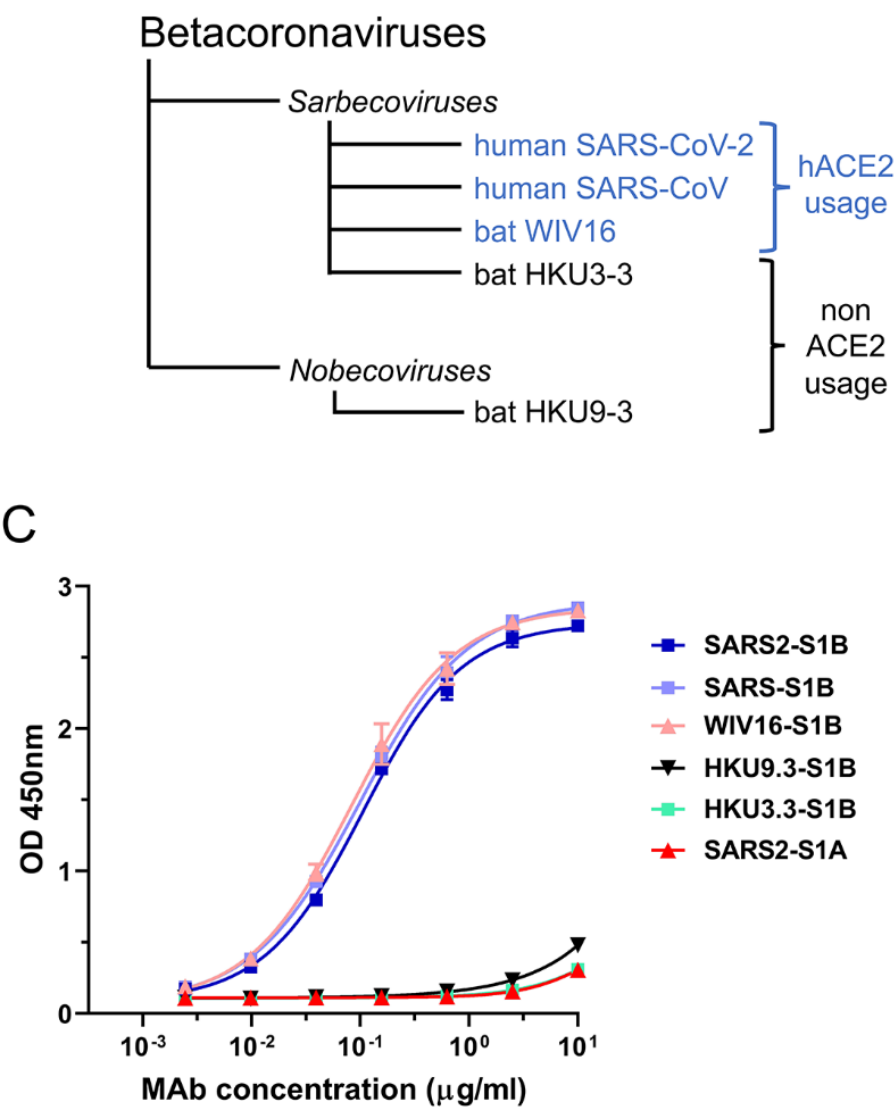

SARS2-S1B

- SARS-S1B

WIV16-S1B

HKU9.3-S1B

HKU3.3-S1B

SARS2-S1A

$E$

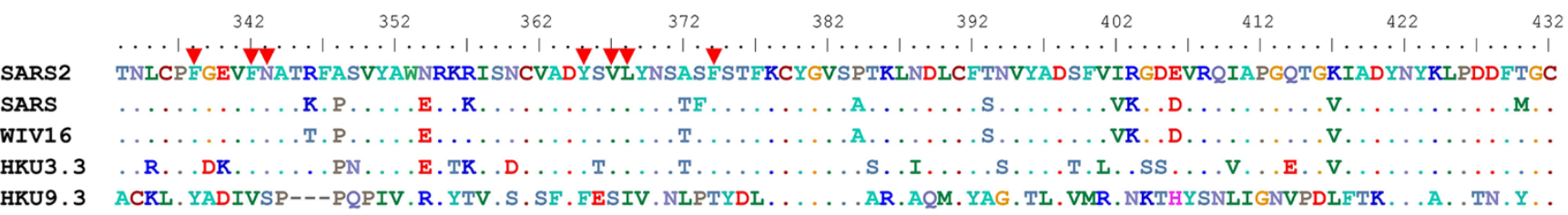

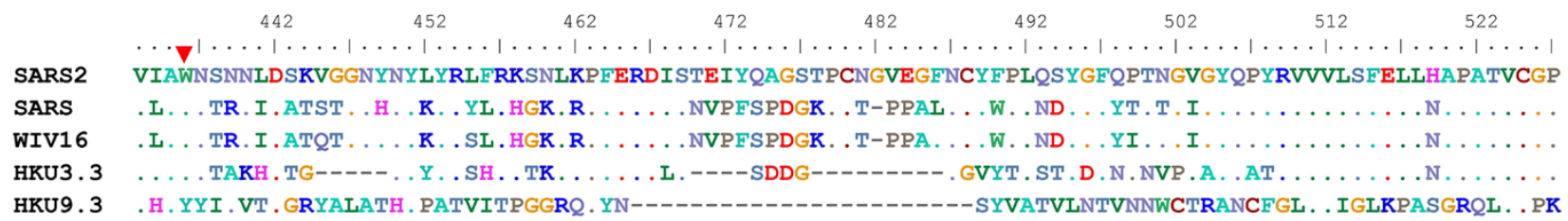

Fig. 5. The 47D11 epitope is conserved in SARS-like viruses. A) Phylogenetic tree of SARS-like viruses RBD used to assess 47D11 binding (63). B) Surface representation of the 47D11 bound RBD colored according to sequence conservation across SARS-CoV, SARS-CoV-2 and 11 SARS-like viruses (Supplementary Figure 5). The 47D11 Fab variable chains are shown as a ribbon diagram and colored grey. Heavy chain residues W102 and F103 are shown as sticks. For comparison, residues 1-84 of the RBD bound ACE2 (PDB ID: 6MOJ) are shown as a silhouette. C) ELISA-binding curves of 47D11 to the S1B domain of SARS, SARS2, WIV16, HKU3-3 and HKU9-3. The average \pm SD from two independent experiments with technical duplicates is shown. D) 47D11-mediated neutralization of infection of luciferase-encoding VSV particles pseudotyped with WIV16-S. An anti-Strep-tag human monoclonal antibody was used as an antibody isotype control. The average \pm SD from two independent experiments is shown. E) Aligned RBD sequences of SARS-CoV-2, SARS-CoV, WIV16, HKU3-3 and HKU9-3. Key residues in the 47D11 epitope are indicated by red arrows. 